\title{
Nonlinear pentagonal intuitionistic fuzzy number and its application in EPQ model under learning and forgetting
}

\author{
Avishek Chakraborty ${ }^{1} \cdot$ Shilpi Pal ${ }^{1} \cdot$ Sankar Prasad Mondal ${ }^{2} \cdot$ Shariful Alam $^{3}$ D
}

Received: 21 January 2021 / Accepted: 19 October 2021 / Published online: 8 December 2021

(c) The Author(s) 2021

\begin{abstract}
In this current era, the concept of nonlinearity plays an important and essential role in intuitionistic fuzzy arena. This article portrays an impression of different representation of nonlinear pentagonal intuitionistic fuzzy number (PIFN) and its classification under different scenarios. A new de-intuitification technique of non-linear PIFN is addressed in this article along with its various graphical representations. Additionally, in this paper, we have observed this by applying it in an economic production quantity model where the production is not perfect and defective items are produced which are reworked. The model is considered under learning and forgetting, where learning is considered as linear, nonlinear PIFN and crisps arena. It is observed from the numerical study that high learning effects in rework lead to decrease in production of defective item, which, besides an economic advantage, may have a positive effect on the environment. Even though forgetting has an adverse effect, the average total cost is much less than that of the basic model which ignores worker learning and forgetting. Finally, comparative and sensitivity analysis result shows the utility of this noble work.
\end{abstract}

Keywords Pentagonal intuitionistic fuzzy number (PIFN) - De-intuitification · EPQ Model · Learning and forgetting · Production inventory management problem

\section{Introduction}

The theory of impreciseness plays a leading role in various fields of modern science and technology due to natural presence of ambiguity, uncertainty in human minds. In the recent past, researchers from distinctive domains like environment and ecology, science and technology, financial mathematics, social media, medical experimental etc. have integrated the impression of vagueness in their relevant domains. In the year 1965, Professor Zadeh [1] put forth an incredible observation regarding the fuzzy set supposition. Few years later, in the year 1972, Chang and Zadeh [2] gave sketch the formative outline of fuzzy development and since then, quite

Shariful Alam

salam50in@yahoo.co.in

1 Department of Basic Science, Narula Institute of Technology, Kolkata 700109, India

2 Department of Natural Science, Maulana Abul Kalam Azad University of Technology, Kolkata, West Bengal 741249, India

3 Department of Mathematics, Indian Institute of Engineering Science and Technology, Shibpur, Howrah, West Bengal 711103, India a lot of works have been recognized in this research arena [3-6] along with the countless progression and upgrading postulations of fuzzy logic. Notably, fuzzy set doesn't mull over the degree of uncertainty, which indicates the degree of non-belongingness. In the year 1986, Professor Atanassov [7] extended and expanded the concept of fuzzy set into intuitionistic fuzzy set (IFS) by incorporating the concept of both membership and non-membership functions of a fuzzy number. Subsequently, as an annex of intuitionistic fuzzy set, Zhang et al. [8] exhibited the concept of interval-valued intuitionistic fuzzy number and discussed its relevance in details. Later on, researchers developed triangular [9], trapezoidal [10] and pentagonal [11] intuitionistic fuzzy numbers to capture, handle and explore various complex features of many real life problems in a nice and meaningful way. Also, researchers developed the application of arithmetic operation [12], assignment difficulty [13], similarity measure and score function [14] in interval-valued intuitionistic fuzzy set. Moreover, multiple attribute decision making problems have been solved in intuitionistic sphere by using constructive operators like aggregation operator [15] and exponential operator [16]. Also, multi criteria decision making (MCDM) methods are developed on the ground of similarity mea- 
sures $[17,18]$, inclusion measure [19], entropy measure [20, 21], cross-entropy measure [22] and distance measures [23]. Researchers applied the intuitionistic fuzzy number in various field of inventory management; for example Chakraborty et al. [24] applied intuitionistic fuzzy optimization technique for Pareto optimal solution of manufacturing inventory models with shortages, De and Sana [25] applied it into multi-period production based model. Furthermore, De et al. [26] introduced time sensitivity backlogging EOQ model, Banerjee and Roy [27] manifested multi-objective stochastic inventory model, Das et al. [28] focused time dependent backlogging EOQ model, Garai et al. [29] proposed generalized intuitionistic fuzzy inventory model, De and Sana [30] ignited intuitionistic fuzzy based backlogging EOQ model, Ali et al. [31] proposed multi objective fractional inventory model and Kaur and Deb [32] established an intuitionistic approach to an inventory model without shortages.

Classical EPQ model (Silver et al. [33]) assumes that the manufacturing process is failure free and all the items produced are of perfect quality. However, in real production environment, it is observed that the defective items are produced due to imperfect production processes. So the defective items must be rejected, repaired and reworked, and the corresponding substantial costs are incurred in the integrated total costing of the inventory system. Recently, numerous researchers are working on EPQ/EOQ models with imperfect quality items. Investment in inventory is essential to upgrade the machinery which will reduce the production of defective items. Dey and Giri [34] investigated a model with investment to reduce the production of defective items. Giri and Glock [35] has addressed on closed loop supply chain model with learning and forgetting during manufacturing and remanufacturing of the returned items. Jaber and Bonney [36] studied the effect of learning and forgetting on the EPQ model with both finite and infinite horizons. Jaber and Guiffrida [37, 38] integrated process quality into the learning curve when an imperfect process produces defects that need to be reworked. Glock and Jaber [39] had discussed multi-stage productioninventory model with learning and forgetting effects, rework and scrap of twice defective items. Several other interesting works [40-47, 54-60] had been published in learning based inventory model. Here, an attempt is made to discuss an EPQ model in a more realistic scenario incorporating few new features like system learning and forgetting as nonlinear PIFN and effect of new investment to improve the production quality and reduce the number of defective items.

\section{Motivation and novelties of the work}

From the literature survey, we noticed that the researchers had mainly focused on linear intuitionistic fuzzy number; they did not consider the non-linearity in case of intuitionistic fuzzy number. But we need non-linear membership functions in many cases especially if it contains any geometrical convexity or concavity. In reality, there are several cases, we need to consider non-linear intuitionistic fuzzy number to capture and handle the underlying uncertainties in a better way. In this research article, we have introduced a generalized nonlinear PIFN to give more flexibility on decision maker's choice. We have introduced nonlinear pentagonal intuitionistic fuzzy number with symmetric and asymmetric representations and it has been successfully applied to an EPQ model where it is assumed that production process follows constant demand and imperfect items undergoes for rework. The paper incorporates the human behavior of learning due to repeated practice and experience along with forgetting due to the gap in the production from one cycle to the next cycle. Here, the workers experience due to learning is considered as symmetric nonlinear PIFN. The details of consideration of uncertain parameter are shown in the Flow Diagram 1. Also in practice, the total production time and produce quantity can't be treated as a constant. Moreover, the numbers of defective items reduce when there is new investment on the machinery items involved in the production process. Thus, we have accounted all these factors in our proposed EPQ model to optimize the total cost (Fig. 1).

\section{Mathematical preliminaries}

Definition 2.1 Intuitionistic fuzzy set: [7] Let a set $X$ be fixed. An IFS $\tilde{A}^{i}$ in $X$ is an object having the form $\tilde{A}^{i}=$ $\left\{\left\langle x, \mu_{\tilde{A}^{i}}(x), \vartheta_{\tilde{A}^{i}}(x)\right\rangle: x \in X\right\}$, where the $\mu_{\tilde{A}^{i}}(x): X \rightarrow$ $[0,1]$ and $\vartheta_{\tilde{A}^{i}}(x): X \rightarrow[0,1]$ define the degree of membership and degree of non-membership respectively, of the element $x \in X$ to the set $\tilde{A}^{i}$, which is a subset of $X$, for every element of $x \in X, 0 \leq \mu_{\tilde{A}^{i}}(x)+\vartheta_{\tilde{A}^{i}}(x) \leq 1$.

Definition 2.2 Pentagonal fuzzy number: [3] A pentagonal fuzzy number $\tilde{A}=\left(a_{1}, a_{2}, a_{3}, a_{4}, a_{5} ; \mu_{\tilde{A}}\right)$ should satisfy the following condition.

1. $\mu_{\tilde{A}}(x)$ is a continuous function in the interval $[0,1]$.

2. $\mu_{\tilde{A}}(x)$ is strictly increasing and continuous function on $\left[a_{1}, a_{2}\right]$ and $\left[a_{2}, a_{3}\right]$.

3. $\mu_{\tilde{A}}(x)$ is strictly decreasing and continuous function on $\left[a_{3}, a_{4}\right]$ and $\left[a_{4}, a_{5}\right]$.

Definition 2.3 Pentagonal Intuitionistic number: [11] A linear Pentagonal Intuitionistic fuzzy number $\left(\widetilde{N_{P e n}}\right)$ is defined as $\widetilde{N_{\text {PenIn }}}=\left[\left(s_{1}, s_{2}, s_{3}, s_{4}, s_{5} \mid t\right) ; \pi\right]$, $\left[\left(h_{1}, h_{2}, h_{3}, h_{4}, h_{5} \mid c\right) ; \sigma\right]$, where $\pi, \sigma \in[0,1]$. The accuracy membership function $\left(\tau_{\tilde{S}}\right): \mathbb{R} \rightarrow[0, \pi]$ and the falsity membership function $\left(\varepsilon_{\tilde{S}}\right): \mathbb{R} \rightarrow[\sigma, 1]$ are defined by: 
Fig. 1 Flow diagram of consideration non-linear membership function of uncertain parameter

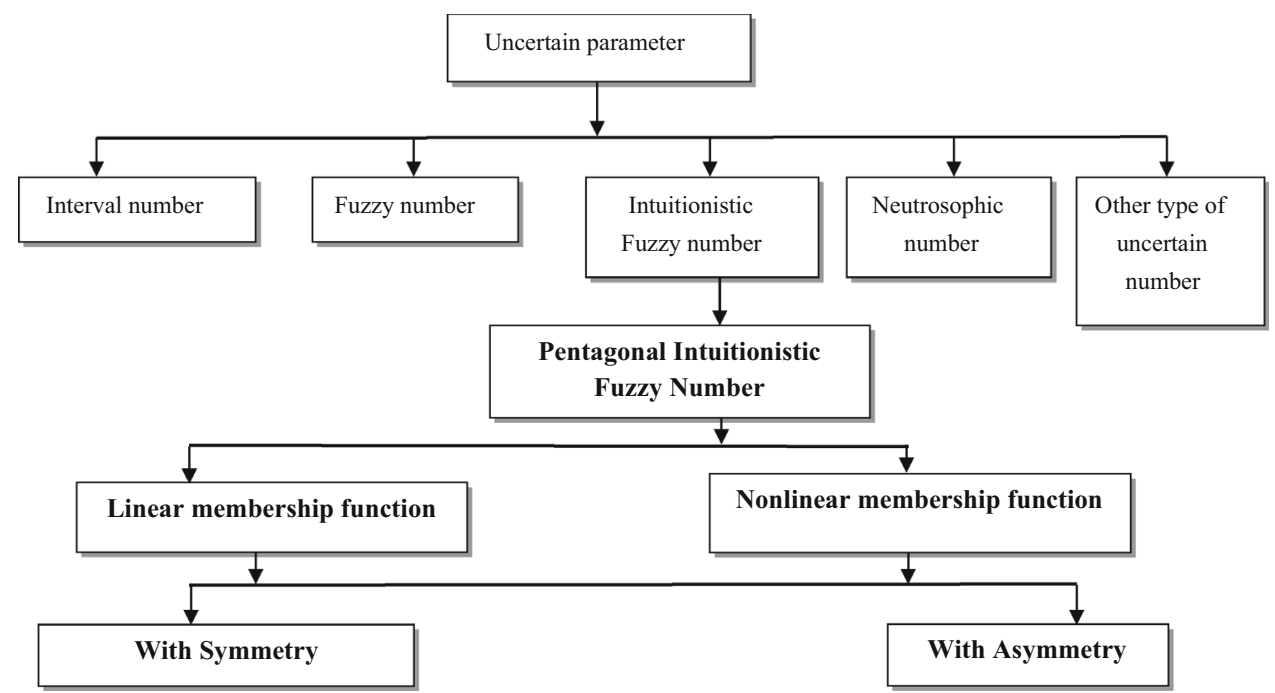

$\pi_{\tilde{A}_{\mathrm{NLPEN}}}(x)=\left\{\begin{array}{ll}t \frac{x-s_{1}}{s_{2}-s_{1}} & \text { if } s_{1} \leq x \leq s_{2} \\ 1-(1-t) \frac{x-s_{2}}{s_{3}-s_{2}} & \text { if } s_{2} \leq x<s_{3} \\ 1 & \text { if } x=s_{3} \\ 1-(1-t) \frac{s_{4}-x}{s_{4}-s_{3}} & \text { if } s_{3}<x \leq s_{4} \\ t \frac{s_{5}-x}{s_{5}-s_{4}} & \text { if } s_{4} \leq x \leq s_{5} \\ 0 & \text { if } x>s_{5}\end{array}, \quad \sigma_{\tilde{A}_{\mathrm{NLPEN}}}(x)= \begin{cases}1-(1-c)\left(\frac{x-h_{1}}{h_{2}-h_{1}}\right)^{n_{1}} & \text { if } h_{1} \leq x \leq h_{2} \\ c\left(\frac{h_{3}-x}{h_{3}-h_{2}}\right)^{n_{2}} & \text { if } h_{2} \leq x<h_{3} \\ 0 & \text { if } x=h_{3} \\ c\left(\frac{h_{4}-x}{h_{4}-h_{3}}\right)^{m_{1}} & \text { if } h_{3}<x \leq h_{4} \\ 1-(1-c)\left(\frac{h_{5}-x}{h_{5}-h_{4}}\right)^{m_{2}} & \text { if } h_{4} \leq x \leq h_{5} \\ 1 & \text { if } x>h_{5} .\end{cases}\right.$

\section{Nonlinear Pentagonal Intuitionistic fuzzy number with asymmetry}

Definition 3.1: A non-linear Pentagonal Intuitionistic fuzzy number (NLPIFN) with asymmetry can be written as, $\widetilde{A}_{\mathrm{NLPEN}}=\left[\left\{\left(g_{1}, g_{2}, g_{3}, g_{4}, g_{5} ; s, t\right)_{\left(n_{1}, n_{2} ; m_{1}, m_{2}\right)} ; \pi_{\tilde{A}_{\mathrm{NLPEN}}}\right.\right.$ $\left.(x)\}, \quad\left\{\left(h_{1}, h_{2}, h_{3}, h_{4}, h_{5} ; c, d\right)_{\left(n_{1}, n_{2} ; m_{1}, m_{2}\right)} ; \sigma_{\tilde{A}_{\mathrm{NLPEN}}}(x)\right\}\right]$ where membership and non-membership function can be explained as,

$\pi_{\tilde{A}_{\mathrm{NLPEN}}}(x)=\left\{\begin{array}{ll}s\left(\frac{x-g_{1}}{g_{2}-g_{1}}\right)^{n_{1}} & \text { if } g_{1} \leq x \leq g_{2} \\ 1-(1-s)\left(\frac{x-g_{2}}{g_{3}-g_{2}}\right)^{n_{2}} & \text { if } g_{2} \leq x<g_{3} \\ 1 & \text { if } x=g_{3} \\ 1-(1-t)\left(\frac{g_{4}-x}{g_{4}-g_{3}}\right)^{m_{1}} & \text { if } g_{3}<x \leq g_{4} \\ t\left(\frac{g_{5}-x}{g_{5}-g_{4}}\right)^{m_{2}} & \text { if } g_{4} \leq x \leq g_{5} \\ 0 & \text { if } x>g_{5}\end{array} \quad \sigma_{\tilde{A}_{\mathrm{NLPNN}}}(x)= \begin{cases}1-(1-c)\left(\frac{x-h_{1}}{h_{2}-h_{1}}\right)^{n_{1}} & \text { if } h_{1} \leq x \leq h_{2} \\ c\left(\frac{h_{3}-x}{h_{3}-h_{2}}\right)^{n_{2}} & \text { if } h_{2} \leq x<h_{3} \\ 0 & \text { if } x=h_{3} \\ d\left(\frac{h_{4}-x}{h_{4}-h_{3}}\right)^{m_{1}} & \text { if } h_{3}<x \leq h_{4} \\ 1-(1-d)\left(\frac{h_{5}-x}{h_{5}-h_{4}}\right)^{m_{2}} & \text { if } h_{4} \leq x \leq h_{5} \\ 1 & \text { if } x>h_{5} .\end{cases}\right.$
Definition $3.2 \alpha, \beta$-cut form of NLPIFNAS: The $\alpha, \beta$-cut form of NLPIFNAS is classified as follows 


$$
\begin{aligned}
A_{\alpha, \beta}= & \left\{x \in X \mid \pi_{\tilde{A}_{N L P E N}}(x) \geq \alpha, \sigma_{\tilde{A}_{N L P E N}}(x) \geq \beta\right\} \\
= & \begin{cases}A_{1 L}(\alpha)=g_{1}+\left(\frac{\alpha}{s}\right)^{1 / n_{1}}\left(g_{2}-g_{1}\right) & \text { for } \alpha \in[0, s] \\
A_{2 L}(\alpha)=g_{2}+\left(\frac{1-\alpha}{1-s}\right)^{1 / n_{2}}\left(g_{3}-g_{2}\right) & \text { for } \alpha \in[s, 1] \\
A_{2 R}(\alpha)=g_{4}-\left(\frac{1-\alpha}{1-t}\right)^{1 / m_{1}}\left(g_{4}-g_{3}\right) & \text { for } \alpha \in[t, 1] \\
A_{1 R}(\alpha)=g_{5}-\left(\frac{\alpha}{t}\right)^{1 / m_{2}}\left(g_{5}-g_{4}\right) & \text { for } \alpha \in[0, t]\end{cases}
\end{aligned}
$$

1. Anyone can understand the relationship between fuzzy where, $A_{1 L}(\alpha), A_{2 L}(\alpha)$ is the increasing function based on $\alpha, \beta$ and $A_{2 R}(\alpha), A_{1 R}(\alpha)$ is the decreasing function corresponding to $\alpha, \beta$.

Note: 3.1: If $g_{3}=h_{3}, n_{1}=n_{2}=m_{1}=m_{2}=1$, as a result of non-linear Pentagonal Intuitionistic fuzzy number is converted into linear asymmetrical Pentagonal Intuitionistic fuzzy number.

Note: 3.2: If $g_{3}=h_{3}, c=d, s=t$, then nonlinear Pentagonal Intuitionistic fuzzy number is converted into non-linear partial symmetrical Pentagonal Intuitionistic fuzzy number.

Note: 3.3: If $g_{3}=h_{3}, c=d=s=t$, then non-linear Pentagonal Intuitionistic fuzzy number is converted into nonlinear symmetrical Pentagonal Intuitionistic fuzzy number.

Note: 3.4: If $g_{3}=h_{3}, c=d, s=t, n_{1}=n_{2}=m_{1}=$ $m_{2}=1$ then non-linear Pentagonal Intuitionistic fuzzy number is converted into linear Pentagonal Intuitionistic partial symmetrical fuzzy number.

Note: 3.5: If $g_{3}=h_{3}, c=d=s=t, n_{1}=n_{2}=$ $m_{1}=m_{2}=1$ then non-linear Pentagonal Intuitionistic fuzzy number is converted into linear symmetrical Pentagonal Intuitionistic fuzzy number.

The geometrical representation of different form of pentagonal intuitionistic fuzzy number is shown as follows (Figs. 2, 3, 4, 5, 6, 7).

\section{De-intuitification of non-linear symmetric pentagonal intuitionistic fuzzy number}

\section{Defuzzification methods}

Defuzzification is a process of where fuzzy numbers are transformed in crisp number. In other words, defuzzification is a technique to assign appropriate crisp value to a fuzzy number. There are several popular and standard methods of defuzzification which includes Centre of Area method [48], Bisector of Area method [53], Largest of Maxima method [50], Smallest of Maxima Method [52], Mean of Maxima method [51], etc. Defuzzification process is important for the following two major reasons: number and the crisp number.

2. Finding the crispified value of the fuzzy solutions.

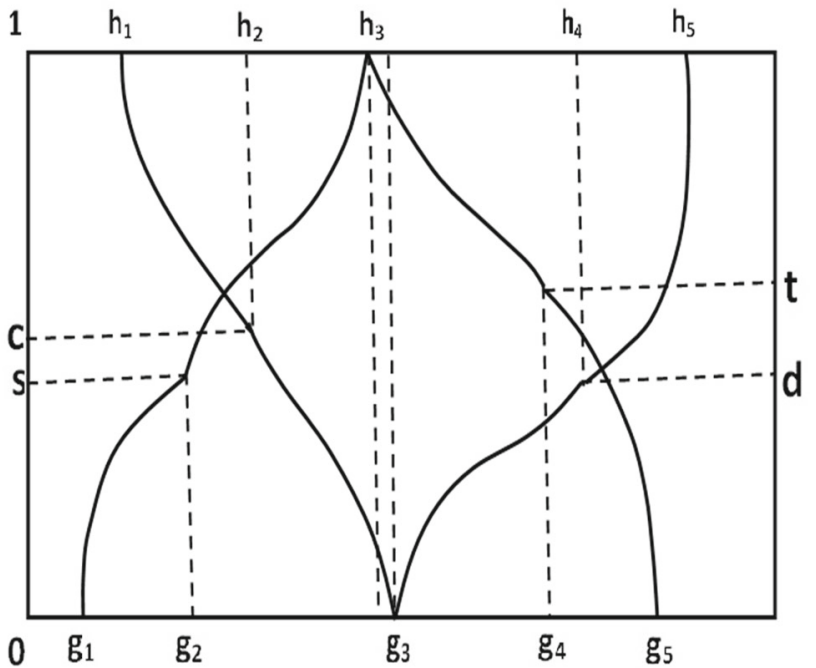

Fig. 2 Non-linear pentagonal intuitionistic fuzzy number having asymmetry

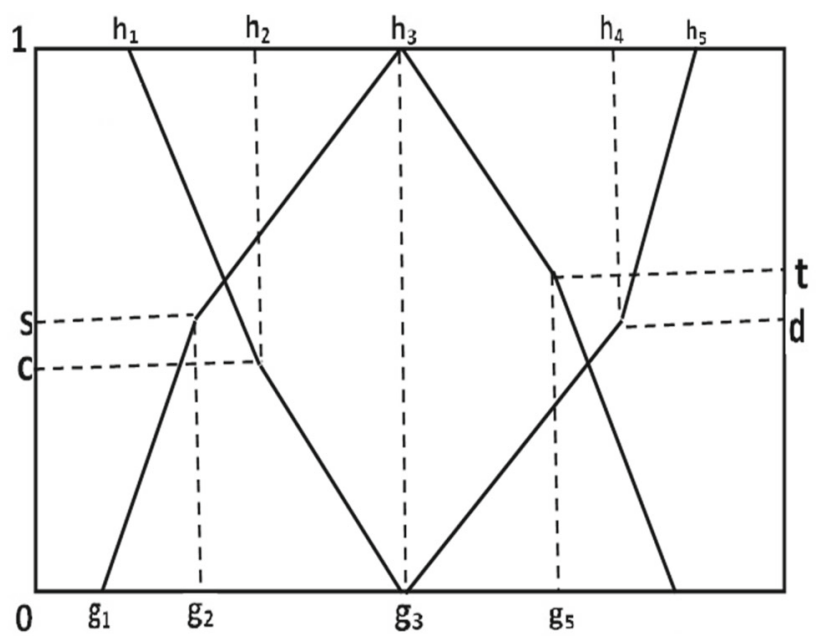

Fig. 3 Linear pentagonal intuitionistic fuzzy number having asymmetry 


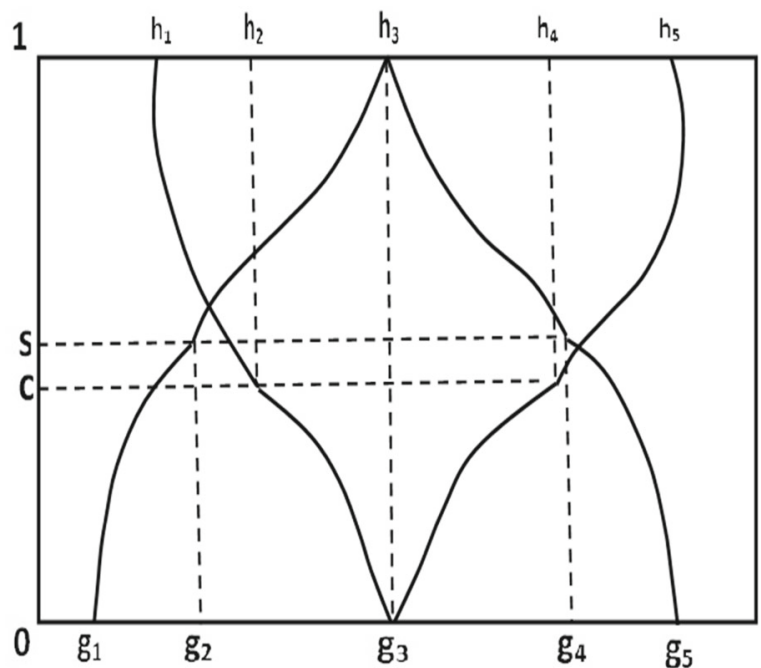

Fig. 4 Non-linear pentagonal intuitionistic fuzzy number having partial symmetry

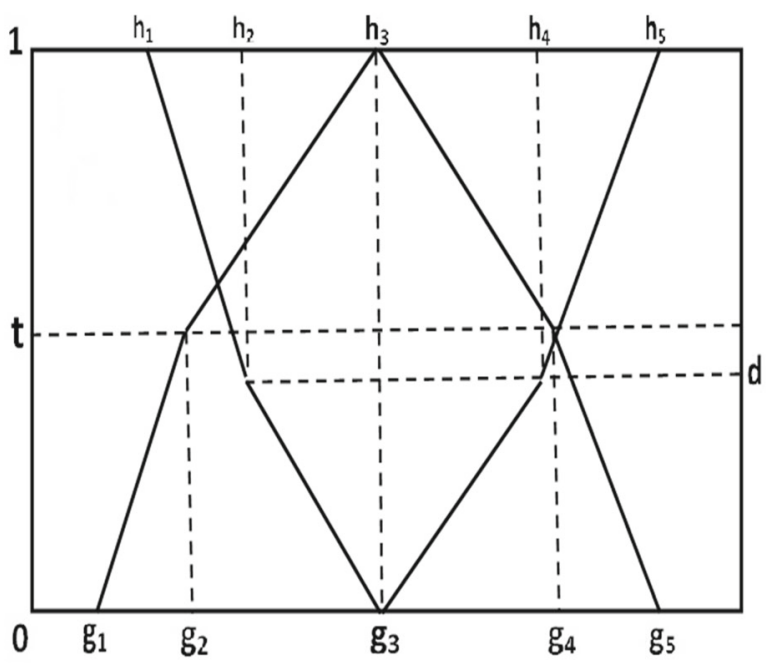

Fig. 5 Linear pentagonal intuitionistic fuzzy number having partial symmetry

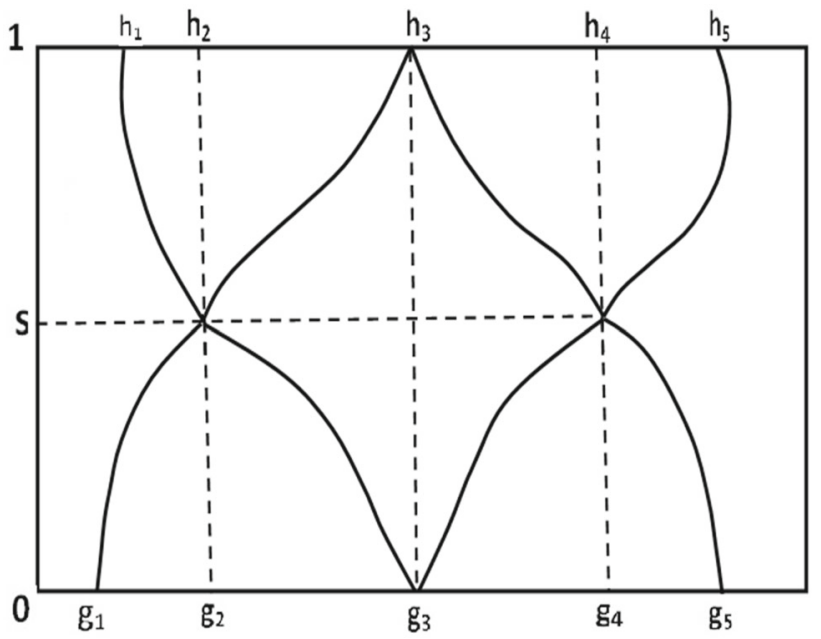

Fig. 6 Non-linear Pentagonal Intuitionistic fuzzy number having symmetry

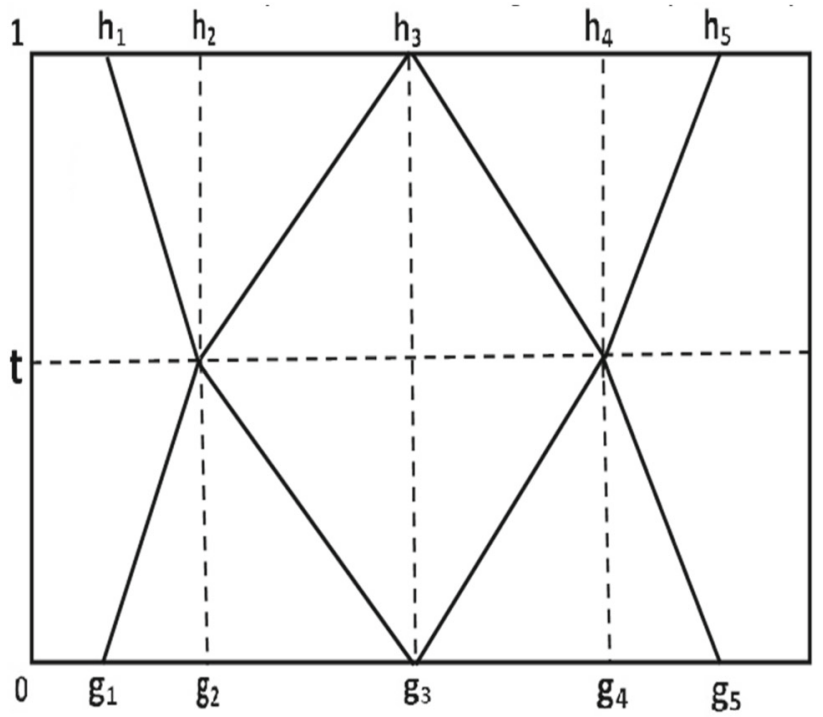

Fig. 7 Linear Pentagonal Intuitionistic fuzzy number having symmetry

\section{De-intuitification of non-linear symmetric pentagonal intuitionistic fuzzy number based on alpha-beta $(\alpha, \beta)$-cut method}

The left and right $\alpha$-cut of a non-linear fuzzy number are,

$\boldsymbol{L}^{-1}(\boldsymbol{\alpha})=g_{1}+\left(\frac{\alpha}{s}\right)^{p_{1}}\left(g_{2}-g_{1}\right)$ for $\alpha \in[0, s], \quad \boldsymbol{R}^{-1}(\boldsymbol{\alpha})=g_{4}-\left(\frac{1-\alpha}{1-s}\right)^{q_{1}}\left(g_{4}-g_{3}\right)$ for $\alpha \in[s, 1]$

$\boldsymbol{L}^{-1}(\boldsymbol{\alpha})=g_{2}+\left(\frac{1-\alpha}{1-s}\right)^{p_{2}}\left(g_{3}-g_{2}\right)$ for $\alpha \in[s, 1], \quad \boldsymbol{R}^{-1}(\boldsymbol{\alpha})=g_{5}-\left(\frac{\alpha}{s}\right)^{q_{2}}\left(g_{5}-g_{4}\right)$ for $\alpha \in[0, s]$

$\boldsymbol{L}^{-1}(\boldsymbol{\beta})=h_{1}+\left(\frac{1-\beta}{1-c}\right)^{p_{1}}\left(h_{2}-h_{1}\right)$ for $\alpha \in[0, c], \quad \boldsymbol{R}^{-1}(\boldsymbol{\beta})=h_{4}-\left(\frac{\beta}{c}\right)^{q_{1}}\left(h_{4}-h_{3}\right)$ for $\alpha \in[c, 1]$

$\boldsymbol{L}^{-1}(\boldsymbol{\beta})=h_{2}+\left(\frac{\beta}{c}\right)^{p_{2}}\left(h_{3}-h_{2}\right)$ for $\alpha \in[c, 1], \quad \boldsymbol{R}^{-1}(\boldsymbol{\beta})=h_{5}-\left(\frac{1-\beta}{1-c}\right)^{q_{2}}\left(h_{5}-h_{4}\right)$ for $\alpha \in[0, c]$. 
We proposed mean of interval method for de- as NLPIFN. In addition to the facts stated above, we have intuitification as follows:

also assumed the following:

$$
\begin{aligned}
& \check{A}=\frac{\int_{\alpha=0}^{1} \frac{\left(\boldsymbol{L}^{-1}(\boldsymbol{\alpha})+\boldsymbol{R}^{-1}(\boldsymbol{\alpha})\right) \mathrm{d} \alpha}{2}+\int_{\alpha=0}^{1} \frac{\left(\boldsymbol{L}^{-1}(\boldsymbol{\beta})+\boldsymbol{R}^{-1}(\boldsymbol{\beta})\right) \mathrm{d} \beta}{2}}{2} \\
& =\frac{\int_{\alpha=0}^{s} \frac{\left(\boldsymbol{L}^{-1}(\boldsymbol{\alpha})+\boldsymbol{R}^{-1}(\boldsymbol{\alpha})\right) \mathrm{d} \alpha}{2}+\int_{\alpha=s}^{1} \frac{\left(\boldsymbol{L}^{-1}(\boldsymbol{\alpha})+\boldsymbol{R}^{-1}(\boldsymbol{\alpha})\right) \mathrm{d} \alpha}{2}+\int_{\beta=0}^{c} \frac{\left(\boldsymbol{L}^{-1}(\boldsymbol{\beta})+\boldsymbol{R}^{-1}(\boldsymbol{\beta})\right) \mathrm{d} \beta}{2}+\int_{\beta=c}^{1} \frac{\left(\boldsymbol{L}^{-1}(\boldsymbol{\beta})+\boldsymbol{R}^{-1}(\boldsymbol{\beta})\right) \mathrm{d} \beta}{2}}{2} \\
& =\left\{\int_{\alpha=0}^{s} \frac{\left(\left\{g_{1}+\left(\frac{\alpha}{s}\right)^{p_{1}}\left(g_{2}-g_{1}\right)\right\}+\left\{g_{5}-\left(\frac{\alpha}{s}\right)^{q_{2}}\left(g_{5}-g_{4}\right)\right\}\right) \mathrm{d} \alpha}{2}+\int_{\alpha=s}^{1} \frac{\left(\left\{g_{2}+\left(\frac{1-\alpha}{1-s}\right)^{p_{2}}\left(g_{3}-g_{2}\right)\right\}+\left\{g_{4}-\left(\frac{1-\alpha}{1-s}\right)^{q_{1}}\left(g_{4}-g_{3}\right)\right\}\right) \mathrm{d} \alpha}{2}\right. \\
& \left.+\int_{\beta=0}^{c} \frac{\left(\left\{h_{1}+\left(\frac{1-\beta}{1-c}\right)^{p_{1}}\left(h_{2}-h_{1}\right)\right\}+\left\{h_{5}-\left(\frac{1-\beta}{1-c}\right)^{q_{2}}\left(h_{5}-h_{4}\right)\right\}\right) \mathrm{d} \beta}{2}+\int_{\beta=c}^{1} \frac{\left(\left\{h_{2}+\left(\frac{\beta}{c}\right)^{p_{2}}\left(h_{3}-h_{2}\right)\right\}+\left\{h_{4}-\left(\frac{\beta}{c}\right)^{q_{1}}\left(h_{4}-h_{3}\right)\right\}\right) \mathrm{d} \beta}{2}\right\} / 2 \\
& =\left\{\frac{g_{1} s+\frac{s\left(g_{2}-g_{1}\right)}{p_{1}+1}+g_{5} s-\frac{s\left(g_{5}-g_{4}\right)}{q_{2}+1}}{2}+\frac{g_{2}(1-s)-\frac{(1-s)\left(g_{4}-g_{3}\right)}{q_{1}+1}+g_{4}(1-s)+\frac{(1-s)\left(g_{3}-g_{2}\right)}{p_{2}+1}}{2}\right.
\end{aligned}
$$

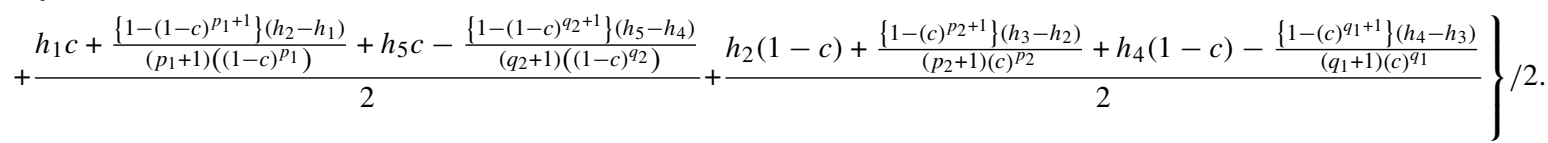

For linear pentagonal intuitionistic fuzzy number we have $p_{1}=1, p_{2}=1, q_{1}=1, q_{2}=1$.

- All items are screened while producing during $T_{1}$ and the

Thus, inspection cost is included in the labour production cost.

$$
\begin{aligned}
\check{A}= & \left\{\frac{g_{1} s+\frac{s\left(g_{2}-g_{1}\right)}{2}+g_{5} s-\frac{s\left(g_{5}-g_{4}\right)}{2}+\frac{g_{2}(1-s)-\frac{(1-s)\left(g_{4}-g_{3}\right)}{2}+g_{4}(1-s)+\frac{(1-s)\left(g_{3}-g_{2}\right)}{2}}{2}}{2}+\frac{h_{2}(1-c)+\frac{\left\{1-(c)^{2}\right\}\left(h_{3}-h_{2}\right)}{2 c}+h_{4}(1-c)-\frac{\left\{1-(c)^{2}\right\}\left(h_{4}-h_{3}\right)}{2 c}}{2}\right\} / 2 . \\
& +\frac{h_{1} c+\frac{\left\{1-(1-c)^{2}\right\}\left(h_{2}-h_{1}\right)}{2(1-c) \cdot}+h_{5} c-\frac{\left\{1-(1-c)^{2}\right\}\left(h_{5}-h_{4}\right)}{2(1-c) \cdot}+\frac{x^{-}}{2}}{2}
\end{aligned}
$$

\section{Application of NIPIFN in EPQ model}

To produce superior quality product with minimum cost, the study of effects of learning and forgetting on production processes has gained much attention in the competitive market. Where learning enhances the procedures or patterns in production systems which optimizes the inventory and increase the throughput, the Forgetting counteracts learning, which may occur as a result of frequent or long interruptions in production. In this paper, we have considered a closed loop EPQ model where the production process is not perfect and all the defective items are sent back to the system for the rework/ correction. During regular production and rework, we have studied the effect of learning which in general uncertain and nonlinear in nature. So we have considered learning curves
- A fixed setup cost is charged for each cycle.

- The demand of the items is dependent on the retail price $p$. Thus we assume that the demand rate of item as $D$ $(p)=a-b p$ where $a, b>0$ and $p<a / b$. The use of symbol $D$ and $D(p)$ is interchangeably throughout the paper.

- The production rate $(P)$ of perfect quality items must always be greater than or equal to the demand rate i.e., $Q(1-\beta) \geq \mathrm{DT}_{1}$ where $\beta$ is the percentage of the defective items. Moreover, the rework rate $(x)$ must always be greater than the demand rate and production of perfect items (i.e., $x>P$ ).

- Learning occurs during the production of finished items (regular and reworked items) which increases the rate of production. Again forgetting occurs during the break in production which reduces the production rate. Thus learn- 
Fig. 8 Inventory of non-defective item

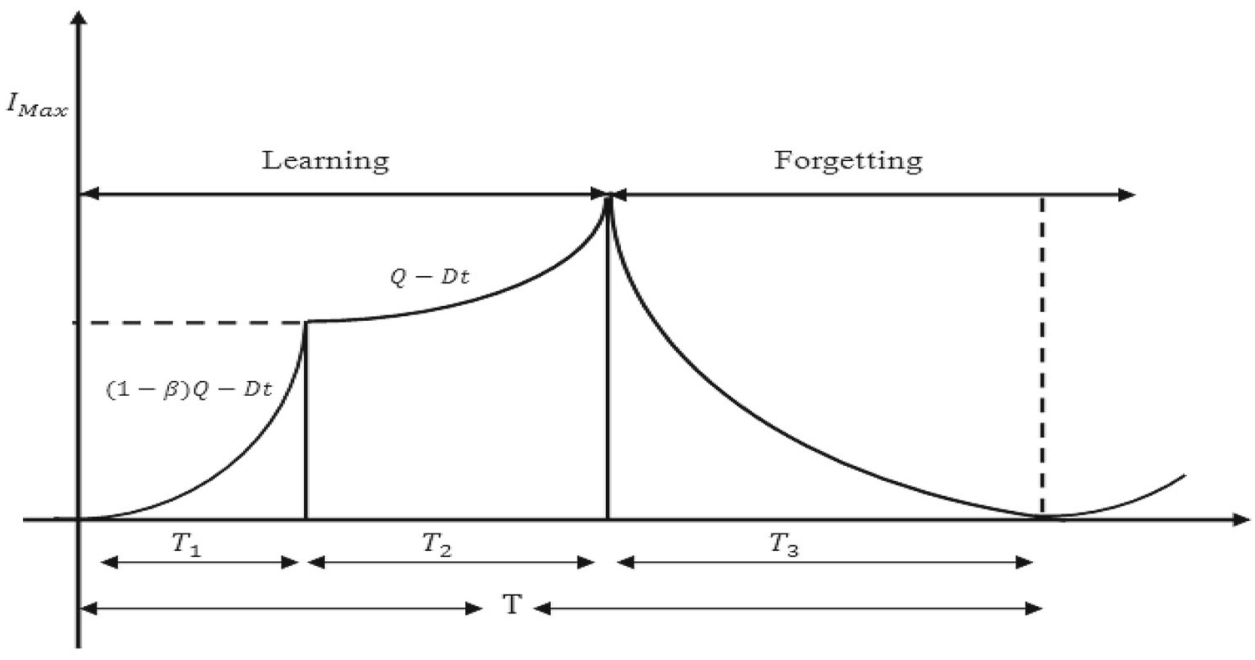

Fig. 9 Inventory of defective item

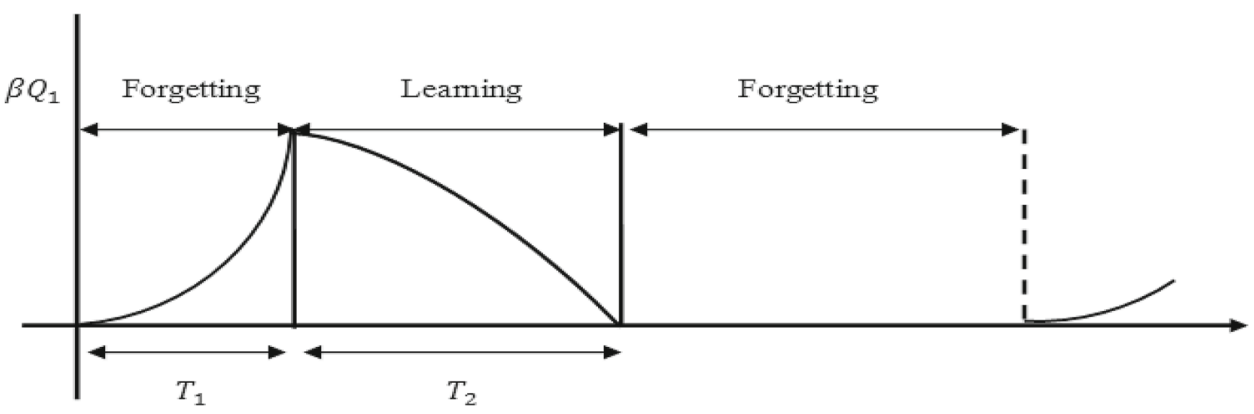

ing and forgetting depends upon the duration of production and break period.

- As learning is uncertain in nature so we consider it as linear, nonlinear PIFN.

- The manufacturer invests money to improve the production process quality by buying new machineries, improving old machine through maintenance and repair, worker training, etc. We consider Porteus [47] logarithmic investment function as $I(\beta)=\frac{1}{\tau} \ln \left(\frac{\beta_{0}}{\beta}\right)$, where $\tau$ is the percentage decrease in $\beta$, per unit of currency increase in investment and $\beta_{0}$ is the original percentage of defective items produced before investment (Figs. 8, 9).

In this model we have observed that $Q$ quantities of the item are produced in each cycle. The production process is not perfect and hence $\beta \%$ of defective items is produced. Thus $Q(1-\beta)$ are perfect quality items which are produced and are separated by screening process during regular production time $T_{1}$. The $\beta$ Q quantity of defective items are reworked after the regular production processes finishes and the rework process is perfect so no defective items remains in the inventory after $\mathrm{T}_{2}$. The production time is not fixed and it depends on the learning and forgetting effect of the worker. As the time goes on the worker become more experienced and hence requires less time to produce. Also when there is no production the worker forgets the experience they have achieved. Since the tendency of human behavior to simultaneously learn and forget is uncertain so we have considered it in the production process of regular and defective items as trapezoidal dense Fuzzy number. Also manufacturer invests money to reduce the imperfect production.

The following notations are used throughout the paper:

$Q \quad$ Production lot size for each cycle (decision variable)

$D \quad$ Demand rate per unit time

$P \quad$ Production rate of perfect item by the manufacturer in the absence of learning

$x \quad$ Production rate of rework item by the manufacturer in the absence of learning

$T_{1}$ Regular production time

$T_{2}$ Rework time

$T_{3}$ Depletion time

$T \quad$ Cycle time $\left(T=T_{1}+T_{2}+T_{3}\right)$

$a_{1}$ Time to produce first unit of perfect item in the absence of learning $(=1 / P)$

$a_{2}$ Time to produce first unit of rework item in the absence of learning $(=1 / x)$

$l_{1} \quad$ Learning coefficient associated with regular production, $l_{1}=\frac{\ln c_{1}}{\ln 2}$, where $C_{1}$ is learning rate in regular production $\left(0<l_{1}<1\right)$ 
Table 1 Literature survey of different EPQ models along with the underlying features

\begin{tabular}{|c|c|c|c|c|c|c|}
\hline Authors & Model type & $\begin{array}{l}\text { Learning in regular } \\
\text { production }\end{array}$ & Learning rework & Forgetting in production & Investment & NLPIFN \\
\hline $\begin{array}{l}\text { Classical model (Silver } \\
\text { [33]) }\end{array}$ & EPQ & No & No & No & No & No \\
\hline Tsai and Wu [40] & EPQ & Yes & Yes & No & No & No \\
\hline Deyand Giri [34] & EPQ & No & No & No & Yes & No \\
\hline Giriand Glock [35] & EPQ & Yes & Yes (reused item) & Yes & No & No \\
\hline Our model & EPQ & Yes & Yes & Yes & Yes & Yes \\
\hline
\end{tabular}

$l_{2} \quad$ Learning coefficient associated with reworking production, $l_{2}=\frac{\ln c_{2}}{\ln 2}$, where $C_{2}$ is learning rate in reworking production

$f_{1} \quad$ Forgetting coefficient associated with regular production

$f_{2} \quad$ Forgetting coefficient associated with reworking production

$\gamma \quad$ Percentage decrease in defective items per unit currency increase in investment

S Setup cost for each production run

$c_{1}$ Labour production cost per unit item per unit time (inspection cost is included)

$c_{2}$ Repair cost of per unit imperfect quality items per unit time

$h_{1}$ Holding cost for each perfect item (i.e., serviceable item) per unit time

$h_{2} \quad$ Holding cost for each imperfect quality item being reworked per unit time

$\beta \quad$ Fraction of defective item

$\vartheta \quad$ Factional opportunity cost

TC Total cost for each cycle

$T_{i} \quad$ Total time elapsed for $i$ th cycle $\left(T_{i}=T_{1 i}+T_{2 i}+T_{3 i}\right)$

\section{Model development and analysis}

Researchers have worked on EPQ model under learning and forgetting along with various constrains. Here, we have tabulated a comparison Table 1 to show the novelty of our work.

\section{Learning and forgetting in regular production}

We use Wright's [46] formulation of the learning effect is used to characterize the learning phenomenon of human. He proposes the relation between man hour required to produce unit item and cumulative production which is written as,

$\tau_{1 j}=a_{1} j^{-l_{1}}$,

where $\tau_{1 j}$ denotes time to produce $j$ th unit during regular production and $a_{1}=\frac{1}{P}$. After the end of the production, forgetting occurs until the next production cycle begins. Let
$E_{1 i}$ denote the experience (the amount learnt in equivalent unit) acquired in the beginning of $i$ th production cycle which is transmitted from $(i-1)$ th cycle. Then $E_{1 i}$ is given by Jaber and Bonney [36]

$E_{1 i}=\left(E_{1\left(i-{ }^{\prime} 1\right)}+Q\right)^{1+\frac{f_{1}}{l_{1}}} \quad S_{1(i-1)}^{-\frac{f_{1}}{l_{1}}}, i=1,2,3 \ldots ; E_{11}=0$,

where $f_{1}$ is the forgetting exponent during regular production run and $S_{1(i-1)}$ is the total number of units that could have been produced in the $(i-1)$ th cycle if there had been no disruption in the regular production process. If there is no forgetting i.e. $f_{1}=0$ then $E_{1 i}=(i-1) Q$. For partial transfer of learning or partial forgetting during regular production we have $0<E_{1 i}<(i-1) Q, \quad i=2,3, \ldots$ Then by Jaber and Bonney [36] $\mathrm{S}_{1 \mathrm{i}}$ is given as,

$\begin{aligned} S_{1 i}= & {\left[\frac{1-l_{1}}{a_{1}}\left(T_{i}-T_{1 i}\right)+\left(E_{1 i}+Q\right)^{\left(1-l_{1}\right)}\right]^{\frac{1}{1-l_{1}}}, } \\ & i=1,2,3, \ldots,\end{aligned}$

where $T_{1 \mathrm{i}}$ is the regular production time and $T_{\mathrm{i}}$ is the total time of the given $i$ th cycle and $T_{1 \mathrm{i}}$ is given by,

$$
\begin{aligned}
T_{1 i} & =\int_{E_{1 i}}^{E_{1 i}+Q} a_{1} j^{-l_{1}} \mathrm{~d} j \\
& =\frac{a_{1}}{1-l_{1}}\left(\left(E_{1 i}+Q\right)^{1-l_{1}}-E_{1 i}^{1-l_{1}}\right) .
\end{aligned}
$$

Now to evaluate the various inventory costs, we define a constant $b_{1 \mathrm{i}}>0$ such that $E_{1 i}=b_{1 i} Q_{1 i}, \quad$ so $0 \leq b_{1 i} \leq$ $i-1, \quad i=2,3, \ldots$. Thus Eq. (4) becomes

$T_{1 i}=\frac{a_{1}}{1-l_{1}}\left(\left(b_{1 i}+1\right)^{1-l_{1}}-b_{1 i}^{1-l_{1}}\right) Q_{1 i}^{1-l_{1}}$.

So,

$Q_{1 i}=\left[\frac{1-l_{1}}{a_{1}} T_{1 i} \frac{1}{\left(\left(b_{1 i}+1\right)^{1-l_{1}}-b_{1 i}^{1-l_{1}}\right)}\right]^{\frac{1}{1-l_{1}}}$. 
So for simplicity we use the symbol Q to represent $Q_{1 i}$, which is interchangeable so, $Q=Q_{1 i}=Q_{1 i}\left(T_{1 i}\right)$.

Thus for any time $t$ the production quantity during the regular production run is

$Q(t)=Q_{1 i}(t)=\left[\frac{1-l_{1}}{a_{1}} t \frac{1}{\left(\left(b_{1 i}+1\right)^{1-l_{1}}-b_{1 i}^{1-l_{1}}\right)}\right]^{\frac{1}{1-l_{1}}}$.

\section{Learning and forgetting during rework of defective items}

As $\beta Q$ quantity of defective items has been reworked so similar to the regular production run, the rework is also subject to human behavior of learning and forgetting. If the rework rate is $x$ (where $x>P$ ), then the time to rework the first item is $1 / x$. Thus time to inspect the $j$ th unit is given by,

$\tau_{2 j}=a_{2} j^{-l_{2}}$ where $a_{2}=\frac{1}{x}$.

Thus $\tau_{21}\left\langle\frac{1}{P}\right.$ as $\left.x\right\rangle P$. If $E_{2 i}$ denotes the experience gathered during rework (equivalent number of items reworked) which is transferred from $(i-1)$ th cycle to $i$ th cycle is given as before,

$E_{2 i}=\left(E_{2(i-') 1)}+\beta Q\right)^{1+\frac{f_{2}}{T_{2}}} \quad S_{2(i-1)}^{-\frac{f_{2}}{l_{2}}}, i=1,2,3 \ldots ;$

$E_{21}=0$,

where $S_{2 i}$ is the total number of items that could have been produced in the $i$ th cycle if there were no disruption in the rework production process. If there is no forgetting i.e. $f_{2}=$ 0 then $E_{2 i}=(i-1) \beta Q$. For partial transfer of learning or partial forgetting during rework of defective items we have $0<E_{2 i}<(i-1) \beta Q, \quad i=2,3, \ldots$ Then $S_{2 i}$ can be obtained as,

$$
\begin{aligned}
S_{2 i}= & {\left[\frac{1-l_{2}}{a_{2}}\left(T_{i}-T_{1 i}-T_{2 i}+T_{1(i+1)}\right)+\left(E_{2 i}+Q\right)^{\left(1-l_{2}\right)}\right]^{\frac{1}{1-l_{2}}}, } \\
& i=1,2,3, \ldots,
\end{aligned}
$$

where $T_{1(\mathrm{i}+1)}$ is the regular production time of $(i+1)$ th cycle where the defective items are produced and accumulated but is not reworked during that time since the rework of items are discontinued during $\left[T_{2 i}, T_{1(i+1)}\right]$. So there is chance of forgetting till $T_{1(\mathrm{i}+1)}$.
Thus the rework time $T_{2 \mathrm{i}}$ in the $i$ th cycle,

$$
\begin{aligned}
T_{2 i} & =\int_{E_{2 i}}^{E_{2 i}+Q} a_{2} j^{-l_{2}} \mathrm{~d} j \\
& =\frac{a_{2}}{1-l_{2}}\left(\left(E_{2 i}+Q\right)^{1-l_{2}}-E_{2 i}^{1-l_{2}}\right) .
\end{aligned}
$$

Now to evaluate the various inventory costs, we define a constant $\mathrm{b}_{2 \mathrm{i}}>0$ such that $E_{2 i}=b_{2 i} Q_{2 i}$, so $0 \leq b_{2 i} \leq i-1$, $i=2,3, \ldots$. Thus Eq. (4) becomes

$T_{2 i}=\frac{a_{2}}{1-l_{2}}\left(\left(b_{2 i}+1\right)^{1-l_{2}}-b_{2 i}^{1-l_{2}}\right) Q_{2 i}^{1-l_{2}}$.

So,

$Q_{2 i}\left(T_{2 i}\right)=\left[\frac{1-l_{2}}{a_{2}} T_{2 i} \frac{1}{\left(\left(b_{2 i}+1\right)^{1-l_{2}}-b_{2 i}^{1-l_{2}}\right)}\right]^{\frac{1}{1-l_{2}}}$.

Thus for any time $t$ the production quantity during the regular production run is

$Q_{2 i}(t)=\left[\frac{\left(1-l_{2}\right) t}{a_{2}\left(\left(b_{2 i}+1\right)^{1-l_{2}}-b_{2 i}^{1-l_{2}}\right)}\right]^{\frac{1}{1-l_{2}}}$.

\section{Inventory level of the non-defective and defective items}

There is always a demand of non-defective items in the entire replenishment cycle $T$. But during $T_{1 \mathrm{i}}$ the manufacturer has to hold both defective and non-defective items. During $T_{2 \mathrm{i}}$ the defective items are reworked and thus the inventory has only perfect items, partially reworked items and rest are originally perfectly produced items.

Inventory level of non-defective item The inventory level of the non-defective items at any time $t$ is given by

$$
\begin{gathered}
I_{1 i}(t)=(1-\beta) Q_{1 i}(t)-D t, \quad 0 \leq t \leq T_{1 i}, \\
I_{2 i}(t)=Q_{2 i}(t)-D t+(1-\beta) Q_{1 i}\left(T_{1 i}\right) \\
-D T_{1 i}, \quad 0 \leq t \leq T_{2 i}
\end{gathered}
$$

$I_{3 i}(t)=I_{\max }-D t, 0 \leq t \leq T_{3 i}$

where $Q_{1 i}\left(T_{1 i}\right)$ is the total quantity produced of which $(1-\beta) Q_{1 i}\left(T_{1 i}\right)$ is perfect items and $\beta Q_{1 i}\left(T_{1 i}\right)$ is defective and thus $\beta Q_{1 i}\left(T_{1 i}\right)=Q_{2 i}\left(T_{2 i}\right)$. Also $I_{\text {max }}$ is the maximum inventory of non-defective items after rework and it is given by $I_{\max }=Q_{1 i}-D\left(T_{1 i}+T_{2 i}\right)$ and thus the depletion time 
$\mathrm{T}_{3 \mathrm{i}}$ where there is no production in the system but there is constant demand of item in the market is given by $T_{3 i}=\frac{I_{\max }}{d}$.

Inventory level of defective item (yet to rework) The inventory level of defective item which are not yet reworked is given for any time $t$ is

$I_{4 i}(t)=\beta Q_{1 i}(t), \quad 0 \leq t \leq T_{1 i}$,

$I_{5 i}(t)=\beta Q_{1 i}\left(T_{1 i}\right)-Q_{2 i}(t), \quad 0 \leq t \leq T_{2 i}$.

Since during $\mathrm{T}_{2 \mathrm{i}}$ there are defective items which are yet to rework.

\section{Various cost incurred in the inventory}

To maintain an inventory the retailer has to abide certain costs which can't be ignored. This cost includes holding cost of defective and non-defective items, cost to set machinery and labour (set up cost), cost to rework defective items (rework cost), and cost to reduce the production of defective items (investment cost).

Holding cost (HC) The inventory has to hold both defective and non-defective items during both the duration $\mathrm{T}_{1 \mathrm{i}}$ and $\mathrm{T}_{2 \mathrm{i}}$ in the $i$ th cycle. And only non-defective items during $T_{3 \mathrm{i}}$. Thus $\mathrm{HC}_{\mathrm{i}}=\left(\mathrm{HC}_{\mathrm{ND}}\right)_{\mathrm{i}}+\left(\mathrm{HC}_{\mathrm{D}}\right)_{\mathrm{i}}$.

Thus the holding cost for non-defective items in the $i$ th cycle is $\mathrm{HC}_{\mathrm{ND}}$ and it is given by

$$
\begin{aligned}
\left(\mathrm{HC}_{\mathrm{ND}}\right)_{i}= & h_{1}\left[\int_{0}^{T_{1 i}} I_{1 i}(t) \mathrm{d} t+\int_{0}^{T_{2 i}} I_{2 i}(t) \mathrm{d} t+\int_{0}^{T_{3 i}} I_{3 i}(t) \mathrm{d} t\right] \\
= & h_{1}\left[\int_{0}^{T_{1 i}}\left((1-\beta)\left(\frac{t}{\xi_{i}}\right)^{\frac{1}{1-l_{1}}}-D t\right) \mathrm{d} t\right. \\
& +\int_{0}^{T_{2 i}}\left(Q_{2 i}(t)-D t+(1-\beta) Q_{1 i}\left(T_{1 i}\right)-D T_{1 i}\right) \mathrm{d} t \\
& \left.+\int_{0}^{T_{3 i}}\left(Q_{1 i}-D\left(T_{1 i}+T_{2 i}\right)-D t\right) \mathrm{d} t\right] \\
= & h_{1}\left[\xi_{i} Q_{1 i}^{2\left(1-l_{1}\right)}\left[(1-\beta) Q_{1 i}^{l_{1}}-\frac{D \xi_{i}}{2}\right]+\eta_{i} Q_{1 i}(\beta Q)^{1-l_{2}}\right. \\
& \left.-D T_{1 i} T_{2 i}-\frac{D T_{2 i}^{2}}{2}+\frac{\left(Q_{1 i}-D\left(T_{1 i}+T_{2 i}\right)\right)^{2}}{2 D}\right] \\
= & h_{1}\left[(1-\beta) \xi_{i} Q_{1 i}^{2-l_{1}}+\eta_{i} Q\left(\beta Q_{1 i}\right)^{1-l_{2}}\right. \\
& \left.+\frac{Q_{1 i}^{2}}{2 D}-Q_{1 i}\left(T_{1 i}+T_{2 i}\right)\right],
\end{aligned}
$$

where $\xi_{i}=\frac{a_{1}}{1-l_{1}}\left(\left(b_{1 i}+1\right)^{1-l_{1}}-b_{1 i}^{1-l_{1}}\right), \quad$ and $\quad \eta_{i}=$ $\frac{a_{2}}{1-l_{2}}\left(\left(b_{2 i}+1\right)^{1-l_{2}}-b_{2 i}^{1-l_{2}}\right)$.

Thus the holding cost for defective items in the $\mathrm{i}^{\text {th }}$ cycle is $\mathrm{HC}_{\mathrm{D}}$ and it is given by

$$
\begin{aligned}
\left(\mathrm{HC}_{D}\right)_{i} & =h_{2}\left[\int_{0}^{T_{1 i}} I_{4 i}(t) \mathrm{d} t+\int_{0}^{T_{2 i}} I_{5 i}(t) \mathrm{d} t\right] \\
& =h_{2}\left[\int_{0}^{T_{1 i}} \beta\left(\frac{t}{\xi_{i}}\right)^{\frac{1}{1-l_{1}}} \mathrm{~d} t+\int_{0}^{T_{2 i}}\left(\beta Q_{1 i}-\left(\frac{t}{\eta_{i}}\right)^{\frac{1}{1-l_{2}}}\right) \mathrm{d} t\right] \\
& =h_{2}\left[\frac{1-l_{1}}{2-l_{1}} \beta \xi_{i} Q_{1 i}^{2-l_{1}}+\frac{\eta_{i}}{1-l_{2}}\left(\beta Q_{1 i}\right)^{2-l_{2}}\right] .
\end{aligned}
$$

Thus $\mathrm{HC}_{i}=\left(\mathrm{HC}_{\mathrm{ND}}\right)_{i}+\left(\mathrm{HC}_{D}\right)_{i}$

$$
\begin{aligned}
= & h_{1}\left[(1-\beta) \xi_{i} Q_{1 i}^{2-l_{1}}+\eta_{i} Q\left(\beta Q_{1 i}\right)^{1-l_{2}}+\frac{Q_{1 i}^{2}}{2 D}-Q_{1 i}\left(T_{1 i}+T_{2 i}\right)\right] \\
& +h_{2}\left[\frac{1-l_{1}}{2-l_{1}} \beta \xi_{i} Q_{1 i}^{2-l_{1}}+\frac{\eta_{i}}{1-l_{2}}\left(\beta Q_{1 i}\right)^{2-l_{2}}\right] .
\end{aligned}
$$

\section{Production cost (PC)}

Since the production of all the items depends on work efficiency of the labour, i.e., it depends on the number of items produced per unit time considering learning capacity as well as forgetting behaviour of human nature, the production cost in the $i$ th cycle is given by

$\mathrm{PC}_{i}=c_{1} Q_{1 i} T_{1 i}=c_{1} \xi_{i} Q_{1 i}^{2-l_{1}}$.

\section{Rework cost (RC)}

To amend each defective item per unit time, a cost incurred to rework in $i$ th cycle is $\mathrm{RC}_{i}=c_{2}\left(\beta Q_{1 i}\right) T_{2 i}=c_{2} \eta_{i}$ $\left(\beta Q_{1 i}\right)^{2-l_{2}}$.

\section{Investment cost (IC)}

In this paper, our tendency is to produce better quality items and to reduce the production of defective items. To deal with such an important issue the decision maker has to make certain investments such as machine upgradation, purchase of better quality raw material, hiring of skilled labour, etc. which helps in reduction of defective items. Thus here a logarithmic investment function is used to interpret the investment cost incurred. Thus for $i$ th cycle it is given $\mathrm{IC}_{\mathrm{i}}$

$\mathrm{IC}=\frac{\vartheta}{\tau} \ln \left(\frac{\beta_{0}}{\beta}\right)$,

where $\vartheta$ is the factional opportunity cost. 


\section{Set up cost (SC)}

To start an inventory the retailer has to invest some capital money to buy machinery, maintain the holding place of items, human labour, etc. This cost is considered as constant in each cycle, so for $i$ th cycle $S C_{i}=S_{i}$.

\section{Total cost (TC)}

Thus the sum of all the above cost incurred for the $i$ th cycle is

$$
\begin{aligned}
\mathrm{TC}_{i}= & \frac{1}{T}\left[\mathrm{HC}_{i}+\mathrm{PC}_{i}+\mathrm{RC}_{i}+\mathrm{IC}_{i}+\mathrm{SC}_{i}\right] \\
= & \frac{1}{T}\left[h _ { 1 } \left[(1-\beta) \xi_{i} Q_{1 i}^{2-l_{1}}+\eta_{i} Q\left(\beta Q_{1 i}\right)^{1-l_{2}}\right.\right. \\
& \left.+\frac{Q_{1 i}^{2}}{2 D}-Q_{1 i}\left(T_{1 i}+T_{2 i}\right)\right] \\
& +h_{2}\left[\frac{1-l_{1}}{2-l_{1}} \beta \xi_{i} Q_{1 i}^{2-l_{1}}+\frac{\eta_{i}}{1-l_{2}}\left(\beta Q_{1 i}\right)^{2-l_{2}}\right] \\
& \left.+c_{1} \xi_{i} Q_{1 i}^{2-l_{1}}+c_{2} \eta_{i}\left(\beta Q_{1 i}\right)^{2-l_{2}}+\frac{\vartheta}{\tau} \ln \left(\frac{\beta_{0}}{\beta}\right)+S_{i}\right] \\
= & \frac{S_{i} D}{Q_{1 i}}+\frac{Q_{1 i} h_{1}}{2}+\xi_{i} D Q_{1 i}^{1-l_{1}}\left(c_{1}-h_{1} \beta+h_{2} \beta\left(\frac{1-l_{1}}{2-l_{1}}\right)\right) \\
& +\eta_{i} D \beta^{2-l_{2}} Q_{1 i}^{1-l_{2}}\left(\frac{h_{2}}{1-l_{2}}+c_{2}\right)+\frac{D \vartheta}{Q_{1 i} \tau} \ln \left(\frac{\beta_{0}}{\beta}\right) . \quad
\end{aligned}
$$

Thus the above total cost TC is function of $Q$ and $\beta$.

For $i=1$, we have $E_{11}=E_{21}=0$; and thus $\xi_{i}=$ $\frac{a_{1}}{1-l_{1}}$ and $\eta_{i}=\frac{a_{2}}{1-l_{2}}$. The Eq. (20) takes the form

$$
\begin{aligned}
\operatorname{TC}(p, Q, \beta)= & \frac{S_{i} D}{Q}+\frac{Q h_{1}}{2} \\
& +\frac{a_{1} D Q^{1-l_{1}}}{1-l_{1}}\left(c_{1}-h_{1} \beta+h_{2} \beta\left(\frac{1-l_{1}}{2-l_{1}}\right)\right) \\
& +\frac{a_{2} D \beta^{2-l_{2}} Q^{1-l_{2}}}{1-l_{2}}\left(\frac{h_{2}}{1-l_{2}}+c_{2}\right) \\
& +\frac{D \vartheta}{Q \tau} \ln \left(\frac{\beta_{0}}{\beta}\right) .
\end{aligned}
$$

Since $Q$ is discrete and $\beta$ is continuous so it is not possible to prove analytically that the total $\operatorname{cost} \operatorname{TC}(Q, \beta)$ is jointly convex. Hence we check the optimality we have applied the following algorithm on the total cost.

\section{Algorithm}

Step 1: Set $i=1$ and $\beta=\beta_{0}$.

Step 2: Solve for $\mathrm{Q}$ by $\frac{\partial T C}{\partial Q}=0$ and obtain $Q=Q_{0}$.

Step 3: From the above value of $Q=Q_{0}$ obtain the value of $\beta$ by using $\frac{\partial T C}{\partial \beta}=0$ as $\beta=\beta^{*}$.

Step 4: Again substitute the value $\beta=\beta^{*}$ in step 2 and obtain the optimum value of $\mathrm{Q}$ as $Q=Q^{*}$.

Step 5: Evaluate the optimal average total cost $\widetilde{T C}^{*}$ $\left(Q^{*}, \beta^{*}\right)$ from (21) using $\beta=\beta^{*}$ and $Q=Q^{*}$.

Step 6: Set $i=i+1$ and considering $a_{1(i+1)}=$ $a_{1 i} Q^{-l_{1}}$ and $a_{2(i+1)}=a_{2 i} Q^{-l_{2}}$.

Step 7: If $\left|Q_{i}^{*}-Q_{i-1}^{*}\right|>\varepsilon$ then go to step 2 else $i^{*}=$ $i-1$ and stop.

Thus $i^{*}$ is the number of cycle till we have the maximum learning occurs.

Let us consider the learning during production and rework as non-linear Pentagonal Intuitionistic fuzzy number and then de-intuiting it by the above mentioned technique. Then,

$$
\begin{aligned}
& \tilde{l}_{1}=\left\{\frac{g_{11} s+\frac{s\left(g_{12}-g_{11}\right)}{p_{1}+1}+g_{15} s-\frac{s\left(g_{15}-g_{14}\right)}{q_{2}+1}}{2}+\frac{g_{12}(1-s)-\frac{(1-s)\left(g_{14}-g_{13}\right)}{q_{1}+1}+g_{14}(1-s)+\frac{(1-s)\left(g_{13}-g_{12}\right)}{p_{2}+1}}{2}\right.
\end{aligned}
$$

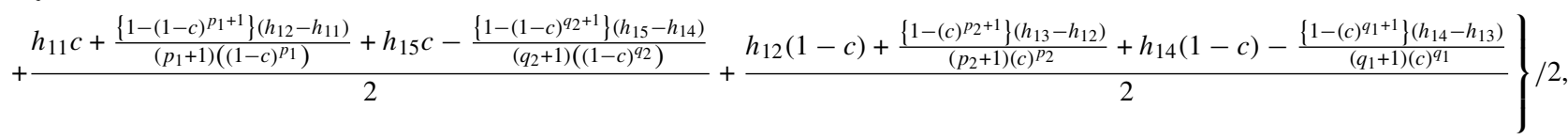

$$
\begin{aligned}
& \tilde{l_{2}}=\left\{\frac{g_{21} s+\frac{s\left(g_{22}-g_{21}\right)}{p_{1}+1}+g_{25} s-\frac{s\left(g_{25}-g_{24}\right)}{q_{2}+1}+\frac{g_{22}(1-s)-\frac{(1-s)\left(g_{24}-g_{23}\right)}{q_{1}+1}+g_{24}(1-s)+\frac{(1-s)\left(g_{23}-g_{22}\right)}{p_{2}+1}}{2}}{2}\right. \\
& \left.+\frac{h_{21} c+\frac{\left\{1-(1-c)^{p_{1}+1}\right\}\left(h_{22}-h_{21}\right)}{\left(p_{1}+1\right)\left((1-c)^{p_{1}}\right)}+h_{25} c-\frac{\left\{1-(1-c)^{q_{2}+1}\right\}\left(h_{25}-h_{24}\right)}{\left(q_{2}+1\right)\left((1-c)^{q_{2}}\right)}}{2}+\frac{h_{22}(1-c)+\frac{\left\{1-(c)^{p_{2}+1}\right\}\left(h_{23}-h_{22}\right)}{\left(p_{2}+1\right)(c)^{p_{2}}}+h_{24}(1-c)-\frac{\left\{1-(c)^{q_{1}+1}\right\}\left(h_{24}-h_{23}\right)}{\left(q_{1}+1\right)(c)^{q_{1}}}}{2}\right\} / 2 .
\end{aligned}
$$


Note 1: for linear pentagonal intuitionistic fuzzy number we have $p_{1}=1, p_{2}=1, q_{1}=1, q_{2}=1$,

Thus,

$$
\begin{aligned}
& \check{l_{1}}=\left\{\frac{g_{11} s+\frac{s\left(g_{12}-g_{11}\right)}{2}+g_{15} s-\frac{s\left(g_{15}-g_{14}\right)}{2}}{2}\right. \\
& +\frac{g_{12}(1-s)-\frac{(1-s)\left(g_{14}-g_{13}\right)}{2}+g_{14}(1-s)+\frac{(1-s)\left(g_{13}-g_{12}\right)}{2}}{2} \\
& +\frac{h_{11} c+\frac{\left\{1-(1-c)^{2}\right\}\left(h_{12}-h_{11}\right)}{2(1-c)^{*}}+h_{15} c-\frac{\left\{1-(1-c)^{2}\right\}\left(h_{15}-h_{14}\right)}{2(1-c)^{5}}}{2} \\
& \left.+\frac{h_{12}(1-c)+\frac{\left\{1-(c)^{2}\right\}\left(h_{13}-h_{12}\right)}{2 c}+h_{14}(1-c)-\frac{\left\{1-(c)^{2}\right\}\left(h_{14}-h_{13}\right)}{2 c}}{2}\right\} / 2, \\
& \check{l_{2}}=\left\{\frac{g_{21} s+\frac{s\left(g_{22}-g_{21}\right)}{2}+g_{25} s-\frac{s\left(g_{25}-g_{24}\right)}{2}}{2}\right. \\
& +\frac{g_{22}(1-s)-\frac{(1-s)\left(g_{24}-g_{23}\right)}{2}+g_{24}(1-s)+\frac{(1-s)\left(g_{23}-g_{22}\right)}{2}}{2} \\
& +\frac{h_{21} c+\frac{\left\{1-(1-c)^{2}\right\}\left(h_{22}-h_{21}\right)}{2(1-c) \cdot}+h_{25} c-\frac{\left\{1-(1-c)^{2}\right\}\left(h_{25}-h_{24}\right)}{2(1-c) \cdot}}{2}
\end{aligned}
$$

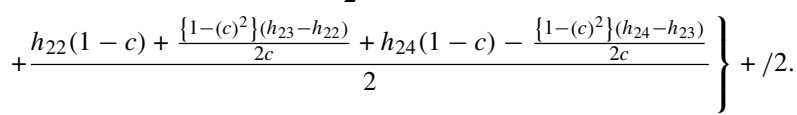

Then,

$$
\begin{aligned}
\widetilde{\operatorname{TC}}(Q, \beta)= & S \frac{D}{Q}+h_{1}\left(\frac{Q}{2}+a_{1} Q^{\widetilde{1}_{1}+1} D\left(\frac{1-\beta}{\widetilde{l_{1}}+2}-\frac{1}{\widetilde{l_{1}}+1}\right)\right. \\
& \left.-\frac{a_{2} D \beta^{\widetilde{l_{2}}+2} Q^{\widetilde{l_{2}+1}}}{\left(\widetilde{l_{2}}+2\right)\left(\widetilde{l_{2}}+1\right)}\right)+c_{1} \frac{a_{1} Q^{\widetilde{l_{1}}} D}{\widetilde{l_{1}}+1}+c_{2} \frac{a_{2} D \beta^{\widetilde{l_{2}}+1} Q^{\widetilde{l_{2}}}}{\left(\widetilde{l_{2}}+1\right)} \\
& +h_{2} D\left(\frac{a_{1} \beta Q^{\widetilde{l_{1}}+1}}{\widetilde{l_{1}}+2}+\frac{a_{2} \beta^{\widetilde{l}_{2}+2} Q^{\widetilde{l_{2}+1}}}{\left(\widetilde{l_{2}}+1\right)\left(\widetilde{l_{2}}+2\right)}\right) \\
& +\frac{\vartheta Q}{\tau D} \ln \left(\frac{\beta_{0}}{\beta}\right) .
\end{aligned}
$$

It is observed that the control parameters are not independent of each other. So to obtain the optimum solution let us acclimatize an iterative algorithm as below.

\section{Numerical study}

A numerical experiment with the following input parameter is conducted whose results are reported further. Also the learning during the normal production and rework time is 95\% (which is equivalent to $l_{12}=0.074$ ).

$$
\begin{aligned}
S & =4000 ; \quad P=150 ; \quad a_{1}=\frac{1}{P} ; \quad x=650 ; \\
a_{2} & =\frac{1}{x} ; \quad l_{1}=0.074 ; \quad l_{2}=0.074 ; \quad h_{1}=2 ; \\
h_{2} & =3 ; \quad \beta_{0}=0.2 ; \quad c_{1}=1 ; \quad c_{2}=10 ; \\
\vartheta & =0.02 ; \quad \tau=0.002 ; \quad \mathrm{TF}=1 ; \quad d=100 .
\end{aligned}
$$

To study the effect of forgetting, we assume that complete forgetting would occur if production and rework are interrupted for a period of one years $\left(\mathrm{T}_{\mathrm{F}}=1\right)$. Then, following Jaber and Bonney [36] we determine the forgetting slopes for production and inspection in the ith cycle as given below:

$$
\begin{aligned}
& f_{1 i}=\frac{l_{1}\left(1-l_{1}\right) \log \left(E_{1 i}+Q\right)}{\log \left(R_{1}+1\right)}, \\
& f_{2 i}=\frac{l_{2}\left(1-l_{2}\right) \log \left(E_{2 i}+\beta Q\right)}{\log \left(R_{2}+1\right)},
\end{aligned}
$$

where $r_{1}=\frac{T_{F}}{T_{1 i}}$ and $R_{2}=\frac{T_{F}}{T_{2 i}}, \quad i=1,2,3, \ldots$

Thus keeping in mind the concept of learning and forgetting in our mind, let us observe how the model works under the crisps and Intuitionistic arena. In Table 2, we observe at which cycle the model will obtain the maximum learning under crisp arena.

From Table 2, we observe that the learning is maximum in $10^{\text {th }}$ cycle.

Since we have introduced a new concept of NLPIFN in the paper so we will observe at which cycle the model will obtain the maximum learning under NLPIFN arena. From
Table 2 Optimal solution till learning occurs in crisps arena

\begin{tabular}{llllllll}
\hline Cycle & $Q^{*}$ & $\beta^{*}$ & $T 1^{*}$ & $T 2^{*}$ & $T 3^{*}$ & $T^{*}$ & Total cost $\left(\mathrm{TC}^{*}\right)$ \\
\hline 1 & 533 & 0.092 & 2.411 & 0.061 & 2.858 & 5.33 & 1521.12 \\
2 & 576 & 0.097 & 1.465 & 0.039 & 4.256 & 5.76 & 1414.47 \\
3 & 598 & 0.105 & 0.912 & 0.026 & 5.042 & 5.98 & 1356.41 \\
4 & 613 & 0.117 & 0.567 & 0.018 & 5.545 & 6.13 & 1321.22 \\
5 & 623 & 0.132 & 0.351 & 0.012 & 5.866 & 6.23 & 1299.67 \\
6 & 626 & 0.154 & 0.216 & 0.008 & 6.035 & 6.26 & 1286.42 \\
7 & 629 & 0.182 & 0.133 & 0.006 & 6.150 & 6.29 & 1278.21 \\
8 & 630 & 0.219 & 0.082 & 0.004 & 6.214 & 6.3 & 1273.07 \\
9 & 631 & 0.267 & 0.050 & 0.003 & 6.256 & 6.31 & 1269.8 \\
10 & 631 & 0.329 & 0.031 & 0.002 & 6.276 & 6.31 & 1267.67 \\
\hline
\end{tabular}


Table 3 Optimal solution till learning occurs in nonlinear Pentagonal Intuitionistic FN arena $p_{1}=p_{2}=q_{1}=q_{2}=2$
Table 4 Optimal solution till learning occurs in linear Pentagonal Intuitionistic FN arena $p_{1}=p_{2}=q_{1}=q_{2}=1$

\begin{tabular}{llllllll}
\hline Cycle & $Q^{*}$ & $\beta^{*}$ & $T 1^{*}$ & $T 2^{*}$ & $T 3^{*}$ & $T^{*}$ & Total cost $(\mathrm{TC})$ \\
\hline 1 & 598 & 0.086 & 0.982 & 0.038 & 4.96 & 5.98 & 1364.93 \\
2 & 630 & 0.166 & 0.122 & 0.008 & 6.171 & 6.3 & 1277.5 \\
3 & 631 & 0.395 & 0.019 & 0.002 & 6.289 & 6.31 & 1266.32 \\
4 & 631 & 0.9 & 0.003 & 0.0006 & 6.306 & 6.31 & 1263.42 \\
\hline
\end{tabular}

\begin{tabular}{llllllll}
\hline Cycle & $Q^{*}$ & $\beta^{*}$ & $T 1^{*}$ & $T 2^{*}$ & $T 3^{*}$ & $T^{*}$ & Total cost $\left(\mathrm{TC}^{*}\right)$ \\
\hline 1 & 544 & 0.091 & 2.180 & 0.058 & 3.202 & 5.44 & 1494.31 \\
2 & 592 & 0.0999 & 1.111 & 0.032 & 4.777 & 5.92 & 1376.92 \\
3 & 612 & 0.114 & 0.586 & 0.019 & 5.515 & 6.12 & 1323.28 \\
4 & 623 & 0.135 & 0.309 & 0.012 & 5.909 & 6.23 & 1295.68 \\
5 & 628 & 0.167 & 0.163 & 0.007 & 6.109 & 6.28 & 1281.22 \\
6 & 630 & 0.213 & 0.086 & 0.005 & 6.209 & 6.30 & 1273.50 \\
7 & 631 & 0.277 & 0.045 & 0.003 & 6.262 & 6.31 & 1269.27 \\
8 & 631 & 0.368 & 0.024 & 0.002 & 6.284 & 6.31 & 1266.84 \\
\hline
\end{tabular}

Table 5 Comparative result of the numerical example

\begin{tabular}{|c|c|c|c|c|c|c|c|c|}
\hline & $\mathrm{Q}^{*}$ & $\beta^{*}$ & $T_{1} *$ & $T_{2} *$ & $T_{3} *$ & $T^{*}$ & Investment & Total cost $\left(\mathrm{TC}^{*}\right)$ \\
\hline $\begin{array}{l}\text { In non-linear PIFN } \\
\quad\left(p_{1}=p_{2}=q_{1}=q_{2}=2\right)\end{array}$ & 598 & 0.0857 & 0.982 & 0.0375 & 4.96 & 5.98 & 8.475 & 1364.93 \\
\hline $\begin{array}{l}\text { In linear PIFN taking } \\
\quad\left(p_{1}=p_{2}=q_{1}=q_{2}=1\right)\end{array}$ & 544 & 0.0909 & & & & 5.44 & 7.885 & 1494.31 \\
\hline In crisps & 533 & 0.0917 & 2.411 & 0.0609 & 2.858 & 5.33 & 7.801 & 1521.12 \\
\hline
\end{tabular}

this Table 3, we will understand the need to take learning as NLPIFN rather than crisp number.

From Table 3, we can see that the learning occurs in 4th cycle only.

Let us also observe how this EPQ model works in linear PIFN arena rather than NLPIFN arena.

From Table4, we can observe that the maximum learning occurs in 8th cycle.

If we compare Tables 2, 3, and 4, we can see that it requires 10 cycles to obtain learning effect under crisps environment while in just 4 cycles to obtain the same in non-linear PIFN arena and 8 cycle in linear PIFA arena. Again more quantity of perfect quality items and less number of defective items are produced under non-linear PIFN arena than under crisps arena. It is also observed that it take less production time $\left(\mathrm{T}_{1}\right)$ in nonlinear Pentagonal Intuitionistic fuzzy number which means learning occurs faster in this arena.

Thus the detail comparative study of our crisps, linear and nonlinear PIFN is done below.

Thus,

from Table 5 and Figs. 10 and 11, if we compare our nonlinear model with our linear or crisp model we can observe that, learning occurs fastest in nonlinear model thus the production of defective item get reduced. Investment

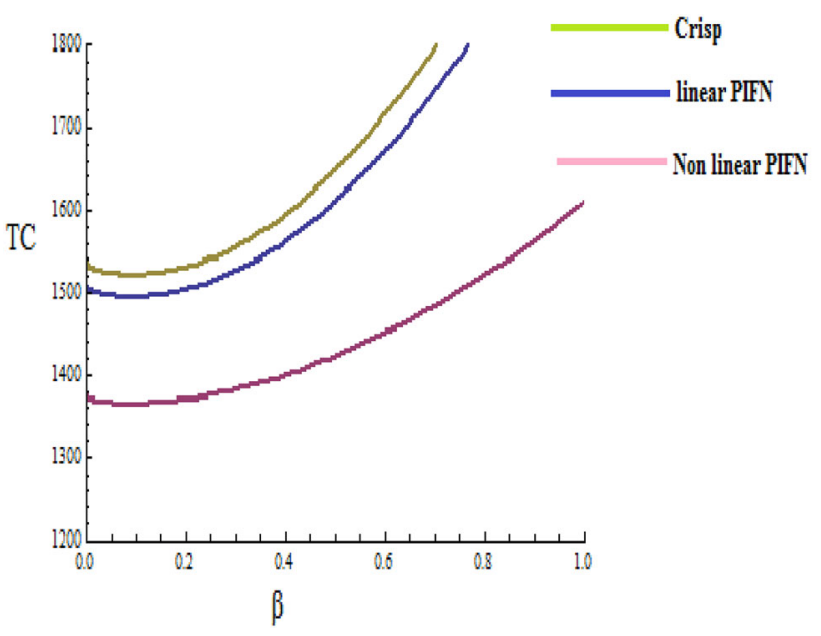

Fig. 10 Behaviour of TC with respect to $\beta$

of money for machine modernization or upgradation also reduces the production of defective items with increase in produced quantity. Also, it is observed that considering learning as NIPIFN, the total cost is minimum as compared with linear PIFN and crisps cases.

Figures 12, 13 and 14 give the 3D plot of total cost vs $Q$ and $\beta$ in three different environments. 


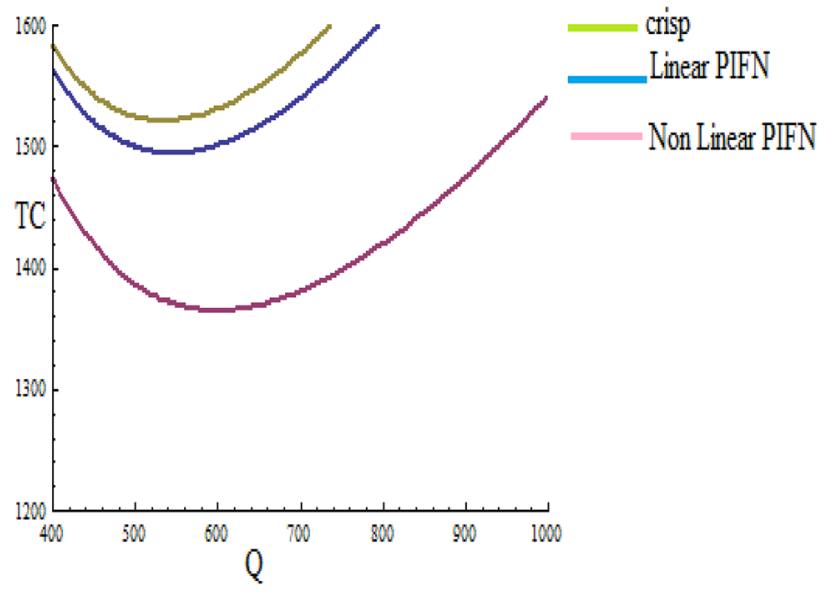

Fig. 11 Behaviour of TC with respect to $Q$

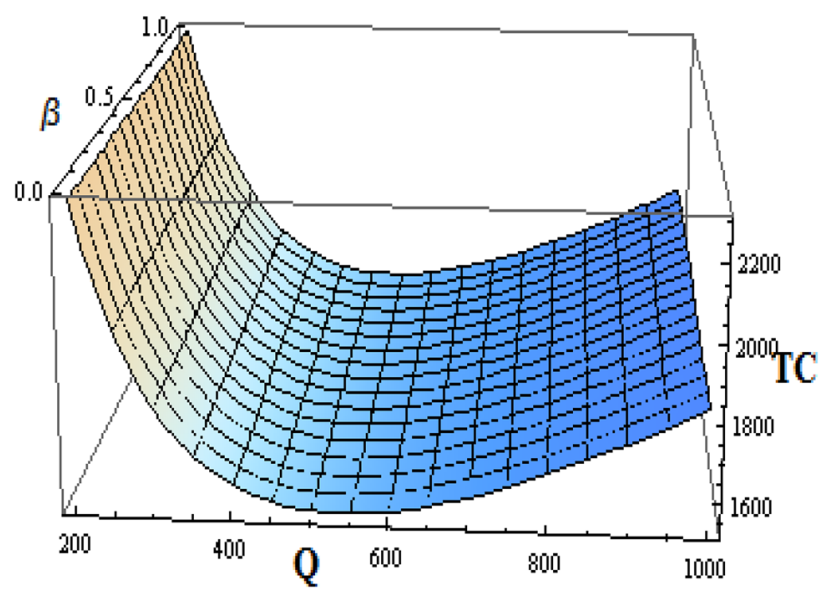

Fig. 12 The 3D Plot of TC with respect to $\beta$ and $Q$ in crisp environment

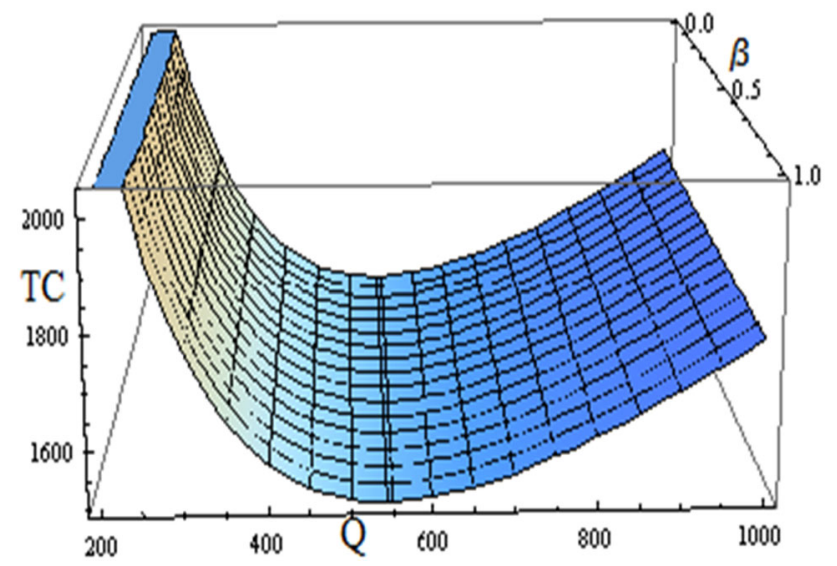

Fig. 13 The 3D Plot of TC with respect to $\beta$ and $Q$ in linear PIFN environment

\section{Sensitivity analysis}

As per the crisps value of Table 1, let us observe the sensitivity of the learning parameter as it is the crucial of all the param-

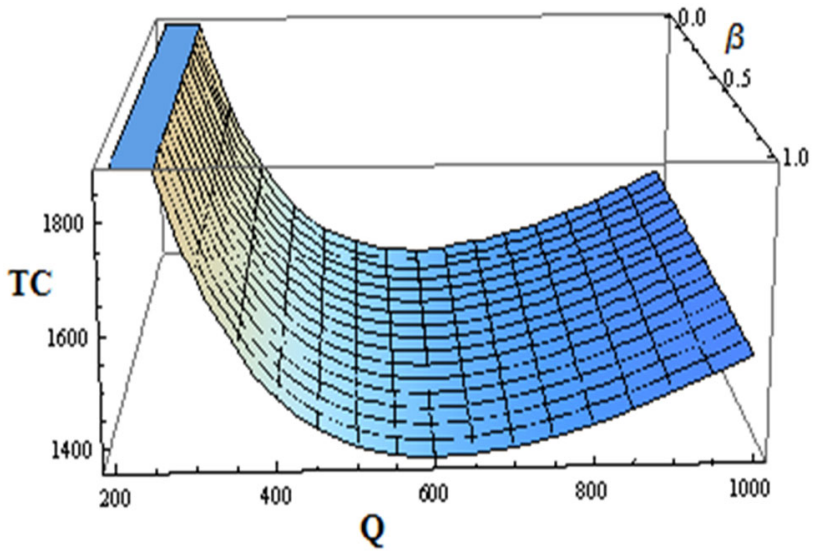

Fig. 14 The 3D Plot of TC with respect to $\beta$ and $Q$ in Nonlinear PIFN environment

eters. With change in learning during regular and rework production, the quantity of the produced items changes a lot. So we have considered learning as uncertain parameter and have observed the sensitivity of learning in crisp arena.

It is observed from the above table that when there is more learning during rework there is less production of defective item. While during more learning in normal production, it takes less time to produce the optimum quantity of items.

\section{Conclusion}

In this article, we initiated the concept of non-linear pentagonal intuitionistic fuzzy number and their graphical classifications. Different forms of PIFN are addressed here along with its geometrical scenario based on symmetry and asymmetry. Also, a new de-intuitification method is developed in nonlinear PIFN arena using alpha/beta cut method. Here we have applied the concept of nonlinear PIFN in an EPQ model effectively where it is assumed that the production process produce imperfect items and it undergoes for rework. Moreover, this article incorporates the human behavior of learning due to repeated practice and experience along with forgetting due to the gap in the production from one cycle to the next cycle. In the existing literatures of EPQ model, we have considered learning and forgetting in the lot sizing model as crisps value. Since both learning and forgetting are human behaviour and it is imprecise, so considering it to be crisps (fixed) is not justified. Therefore, we have considered learning as nonlinear pentagonal intuitionistic fuzzy number. In this article, we also considered the effect of investment to produce better quality item under the effect of learning and forgetting of workers. Here, the workers experience due to learning is considered as symmetric nonlinear PIFN. Several managerial insights can be derived from the numerical analyses presented in this paper. First of all the model gives better 
Table 6 Sensitivity of learning parameter

\begin{tabular}{llllll}
\hline Parameters & Values & Quantity $\left(Q^{*}\right)$ & $\begin{array}{l}\text { Defective fraction } \\
\left(\beta^{*}\right)\end{array}$ & Total cost $(\mathrm{TC} *)$ & Total time $(T)$ \\
\hline$l_{1}$ & $0.322(80 \%)$ & 608 & 0.0478 & 1343.66 & 6.08 \\
& $0.234(85 \%)$ & 591 & 0.0578 & 1384.13 & 5.91 \\
& $0.152(90 \%)$ & 566 & 0.0719 & 1441.74 & 5.66 \\
& $0.0145(99 \%)$ & 501 & 0.1118 & 1602.8 & 5.01 \\
$l_{2}$ & $0.322(80 \%)$ & 536 & 0.229 & 1513 & 5.36 \\
& $0.234(85 \%)$ & 534 & 0.1568 & 1516.97 & 5.34 \\
& $0.152(90 \%)$ & 533 & 0.1166 & 1519.43 & 5.33 \\
& $0.0145(99 \%)$ & 533 & 0.078 & 1522.13 & 5.33 \\
\hline
\end{tabular}

result under nonlinear PIFN arena as learning occurs faster (in four cycle) as compared to linear PIFN or crisps arena. Secondly, the total cost incurred in the production process is very less in nonlinear PIFN arena as compared with other two situations. We also observe from Table 6, that good learning from the system helps the system to reduce the production of defective items. Furthermore, we have noticed that better system learning helps to cut down total production time. On the other hand unit production times increase during interruptions due to a loss of experience/knowledge.

\section{Declarations}

Conflict of interest The authors have no conflict of interest in this research article.

Open Access This article is licensed under a Creative Commons Attribution 4.0 International License, which permits use, sharing, adaptation, distribution and reproduction in any medium or format, as long as you give appropriate credit to the original author(s) and the source, provide a link to the Creative Commons licence, and indicate if changes were made. The images or other third party material in this article are included in the article's Creative Commons licence, unless indicated otherwise in a credit line to the material. If material is not included in the article's Creative Commons licence and your intended use is not permitted by statutory regulation or exceeds the permitted use, you will need to obtain permission directly from the copyright holder. To view a copy of this licence, visit http://creativecomm ons.org/licenses/by/4.0/.

\section{References}

1. Zadeh LA (1965) Fuzzy sets. Inf Control 8:338-353

2. Chang SSL, Zadeh LA (1972) On fuzzy mappings and control. IEEE Trans Syst Man Cybernet 2:30-34

3. Chakraborty A, Mondal SP, Ahmadian A, Senu N, Dey D, Alam S, Salahshour S (2019) The pentagonal fuzzy number: its different representations, properties, ranking, defuzzification and application in game problem. Symmetry 11(2):248. https://doi.org/10. 3390/sym11020248

4. Maity S, Chakraborty A, De SK, Mondal SP, Alam S (2018) A comprehensive study of a backlogging EOQ model with nonlinear heptagonal dense fuzzy environment. Rairo Oper Res. https://doi. org/10.1051/ro/2018114

5. Chakraborty A, Maity S, Jain S, Mondal SP, Alam S (2020) Hexagonal fuzzy number and its distinctive representation, ranking, defuzzification technique and application in production inventory management problem. Granul Comput Springer. https://doi.org/10. 1007/s41066-020-00212-8

6. Guijun W, Xiaoping L (1998) The applications of interval-valued fuzzy numbers and interval distribution numbers. Fuzzy Sets Syst 98(3):331-335

7. Atanassov KT (1986) Intuitionistic fuzzy sets. Fuzzy Sets Syst 20:87-96

8. Zhang X, Yue G, Teng Z (2009) Possibility degree of intervalvalued intuitionistic fuzzy numbers and its application. In: Proceedings of the 2009 International Symposium on Information Processing (ISIP'09) Huangshan, P. R. China, 21-23 August 033-036

9. Li DF, Nan JX, Zhang MJ (2010) A ranking method of triangular intuitionistic fuzzy numbers and application to decision making. Int J Comput Intell Syst 3(5):522-530

10. Rezvani S (2013) Ranking method of trapezoidal intuitionistic fuzzy numbers. Ann Fuzzy Math Inform 5(3):515-523

11. Shapique M (2017) Solutions to fuzzy differential equations using pentagonal intuitionistic fuzzy numbers. MAYFEB J Math 2

12. Dong J, Wan SP (2016) Arithmetic aggregation operators for interval-valued intuitionistic linguistic variables and application to multi-attribute group decision making. Iran J Fuzzy Syst 13(1):1-23

13. Kumar G, Bajaj RK (2014) On solution of interval valued intuitionistic fuzzy assignment problem using similarity measure and score function. Int J Math Comput Phys Electr Comput Eng 8(4):715-720

14. Chong W, Luo P, Li Y, Ren X, (2014) A new similarity measure of interval-valued intuitionistic fuzzy sets considering its hesitancy degree and applications in expert systems. Math Probl Eng. https:// doi.org/10.1155/2014/359214

15. Maoying T, Jing L (2013) Some aggregation operators with interval-valued intuitionistic trapezoidal fuzzy numbers and their application in multiple attribute decision making. Adv Model Optim 15(2):301-308

16. Gou X, Xu Z, Liao H (2016) Exponential operations of intervalvalued intuitionistic fuzzy numbers. Int $\mathbf{J}$ Mach Learn Cybern 7(3):501-518

17. Ye J (2012) Multicriteria decision-making method using the Dice similarity measure based on the reduct intuitionistic fuzzy sets of interval-valued intuitionistic fuzzy sets. Appl Math Model 36(9):4466-4472

18. Luo P, Li YL, Wu C (2013) A new similarity measure of intervalvalued intuitionistic fuzzy sets and its application in commodity recommendation. Int J Inf Technol 3:186-192 
19. Luo Y, Yu C (2008) A fuzzy optimization method for multi-criteria decision making problem based on the inclusion degrees of intuitionistic fuzzy sets. J Inf Comput Sci 3(2):146-152

20. Wei CP, Wang P, Zhang YZ (2011) Entropy, similarity measure of interval-valued intuitionistic fuzzy sets and their applications. Inf Sci 181(19):4273-4286

21. Burillo P, Bustince H (1996) Entropy on intuitionistic fuzzy sets and on interval-valued fuzzy sets. Fuzzy Sets Syst 78(3):305-316

22. Xia M, Xu Z (2012) Entropy/cross entropy-based group decision making under intuitionistic fuzzy environment. Inf Fusion 13(1):31-47

23. Xu ZS, Chen J (2008) An overview of distance and similarity measures of intuitionistic fuzzy sets. Int J Uncertain Fuzziness Knowl Based Syst 16(4):529-555

24. Chakrabortty S, Pal M, Nayak PK (2013) Intuitionistic fuzzy optimization technique for Pareto optimal solution of manufacturing inventory models with shortages. Eur J Oper Res 228(2):381-387

25. De SK, Sana SS (2014) A multi-periods production-inventory model with capacity constraints for multi-manufacturers-a global optimality in intuitionistic fuzzy environment. Appl Math Comput 242:825-841

26. De SK, Goswami A, Sana SS (2014) An interpolating by pass to Pareto optimality in intuitionistic fuzzy technique for a EOQ model with time sensitive backlogging. Appl Math Comput 230:664-674

27. Banerjee S, Roy TK (2010) Solution of single and multiobjective stochastic inventory models with fuzzy cost components by intuitionistic fuzzy optimization technique. Adv Oper Res 2010:1-19

28. Das P, De SK, Sana SS (2015) An EOQ model for time dependent backlogging over idle time: a step order fuzzy approach. Int J Appl Comput Math 1(2):171-185

29. Garai T, Chakraborty D, Roy TK (2018) A multi-item generalized intuitionistic fuzzy inventory model with inventory level dependent demand using possibility mean, variance and covariance. J Intell Fuzzy Syst 35(1):1021-1036

30. De SK, Sana SS (2015) Backlogging EOQ model for promotional effort and selling price sensitive demand-an intuitionistic fuzzy approach. Ann Oper Res 233(1):57-76

31. Ali I, Gupta S, Ahmed A (2019) Multi-objective linear fractional inventory problem under intuitionistic fuzzy environment. Int J Syst Assur Eng Manag 10(2):173-189

32. Kaur P, Deb M (2014) An intuitionistic approach to an inventory model without shortages. Int J Pure Appl Sci Technol 22(2):25

33. Silver EA, Pyke DF, Peterson R (1998) Inventory management and production planning and scheduling. Wiley, New York

34. Dey O, Giri BC (2014) Optimal vendor investment for reducing defect rate in a vendor-buyer integrated system with imperfect production process. Int J Prod Econ 155:222-228

35. Giri BC, Christoph HG (2017) A closed-loop supply chain with stochastic product returns and worker experience under learning and forgetting. Int J Prod Res. https://doi.org/10.1080/00207543. 2017.1347301

36. Jaber MY, Bonney M (1998) The effects of learning and forgetting on the optimal lot size quantity of intermittent production runs. Prod Plan Control 9:20-27

37. Jaber MY, Guiffrida AL (2004) Learning curves for processes generating defects requiring reworks. Eur J Oper Res 159(3):663-672

38. Jaber MY, Guiffrida AL (2008) Learning curves for imperfect production process with reworks and process restoration interruptions. Eur J Oper Res 189(1):93-104

39. Christoph HG, Mohamad YJ (2013) A multi-stage productioninventory model with learning and forgetting effects, rework and scrap. Comput Ind Eng 64:708-720

40. Tsai DM, Wu JC (2012) Economic production quantity concerning learning and the reworking of imperfect items. Yugosl J Oper Res 22(2):313-336
41. Khouja M, Mehrez A (1994) Economic production lot size model with variable production rate and imperfect quality. J Oper Res Soc 45:1405-1417

42. Salameh MK, Abdul-Malak MU, Jaber MY (1993) Mathematical modelling of the effect of human learning in the finite production inventory model. Appl Math Model 17:613-615

43. El-Kassar AN (2009) Optimal order quantity for imperfect quality items. Proc Acad Inf Manag Sci 13(1):24-30

44. Buscher U, Lindner G (2007) Optimizing a production system with rework and equal sized batch shipments. Comput Oper Res 34:515-535

45. Jawlaa P, Singh SR (2016) Multi-item economic production quantity model for imperfect items with multiple production setups and rework under the effect of preservation technology and learning environment. Int J Ind Eng Comput 7:703-716

46. Wright TP (1936) Factors affecting the cost of airplanes. J Aeronaut Sci 3(4):122-28. https://arc.aiaa.org/doi/abs/https://doi.org/ $10.2514 / 8.155$.

47. Porteus EL (1986) Optimal lot sizing, process quality improvement and setup cost reduction. Oper Res 34(1):137-144

48. Cheng CH (1998) A new approach for ranking fuzzy numbers by distance method. Fuzzy Sets Syst 95:307-317

49. Chu T, Tsao C (2002) Ranking fuzzy numbers with an area between the centroid point and original point. Comput Math Appl 43:111-117

50. Liu X (2007) Parameterized defuzzification with maximum entropy weighting function - another view of the weighting function expectation method. Math Comput Model 45(1-2):177-188

51. Deng Y, Zhu ZF, Liu Q (2006) Ranking fuzzy numbers with an area method using of gyration. Comput Math Appl 51:1127-1136

52. Hajjari T (2011) Ranking of fuzzy numbers based on ambiguity degree. Aust J Basic Appl Sci 5(1):62-69

53. Hajjari $T$ (2011) On deviation degree methods for ranking fuzzy numbers. Aust J Basic Appl Sci 5(5):750-758

54. Broumi S, Talea M, Bakali A et al (2019) Shortest path problem in fuzzy, intuitionistic fuzzy and neutrosophic environment: an overview. Complex Intell Syst 5:371-378

55. Pramanik S, Mallick R (2019) TODIM strategy for multi-attribute group decision making in trapezoidal neutrosophic number environment. Complex Intell Syst 5:379-389

56. Chakraborty A, Mondal SP, Alam S et al (2021) Classification of trapezoidal bipolar neutrosophic number, de-bipolarization technique and its execution in cloud service-based MCGDM problem. Complex Intell Syst 7:145-162

57. Das SK, Chakraborty A (2021) A new approach to evaluate linear programming problem in pentagonal neutrosophic environment. Complex Intell Syst 7:101-110

58. Garai T, Garg H (2019) Multi-objective linear fractional inventory model with possibility and necessity constraints under generalised intuitionistic fuzzy set environment. CAAI Trans Intell Technol 4(3): $175-181$

59. Giri SK, Garai T, Garg H, Islam S (2021) Possibilistic mean of generalized non-linear intuitionistic fuzzy number to solve a price and quality dependent demand multi-item inventory model. Comput Appl Math 40(4):1-24

60. Waliv RH, Mishra U, Garg H, Umap HP (2020) A nonlinear programming approach to solve the stochastic multi-objective inventory model using the uncertain information. Arab J Sci Eng 45:6963-6973

Publisher's Note Springer Nature remains neutral with regard to jurisdictional claims in published maps and institutional affiliations. 